\title{
Studies on Silver Ions Releasing Processes and Mechanical Properties of Surface-Modified Titanium Alloy Implants
}

\author{
Aleksandra Radtke ${ }^{1,2}{ }^{\oplus}$, Marlena Grodzicka ${ }^{1,2}$, Michalina Ehlert ${ }^{1,2}$, Tadeusz M. Muzioł ${ }^{1}($, \\ Marek Szkodo ${ }^{3}$, Michał Bartmański ${ }^{3}$ and Piotr Piszczek 1,2,* \\ 1 Faculty of Chemistry, Nicolaus Copernicus University in Toruń, Gagarina 7, 87-100 Toruń, Poland; \\ aradtke@umk.pl (A.R.); marlena.grodzicka@doktorant.umk.pl (M.G.); m.ehlert@doktorant.umk.pl (M.E.); \\ tmuziol@chem.umk.pl (T.M.M.) \\ 2 Nano-Implant Ltd. Jurija Gagarina 5/102, 87-100 Torun, Poland \\ 3 Faculty of Mechanical Engineering, Gdańsk University of Technology, ul. Gabriela Narutowicza 11/12, \\ 80-233 Gdańsk, Poland; marek.szkodo@pg.edu.pl (M.S.); michal.bartmanski@pg.edu.pl (M.B.) \\ * Correspondence: piszczek@umk.pl; Tel.: +48-607-883-357
}

Received: 17 November 2018; Accepted: 6 December 2018; Published: 9 December 2018

\begin{abstract}
Dispersed silver nanoparticles (AgNPs) on the surface of titanium alloy (Ti6Al4V) and titanium alloy modified by titania nanotube layer (Ti6Al4V/TNT) substrates were produced by the chemical vapor deposition method (CVD) using a novel precursor of the formula $\left[\mathrm{Ag}_{5}\left(\mathrm{O}_{2} \mathrm{CC}_{2} \mathrm{~F}_{5}\right)_{5}\right.$ $\left.\left(\mathrm{H}_{2} \mathrm{O}\right)_{3}\right]$. The structure and volatile properties of this compound were determined using single crystal X-ray diffractometry, variable temperature IR spectrophotometry (VT IR), and electron inducted mass spectrometry (EI MS). The morphology and the structure of the produced Ti6Al4V/AgNPs and Ti6Al4V/TNT / AgNPs composites were characterized by scanning electron microscopy (SEM) and atomic force microscopy (AFM). Moreover, measurements of hardness, Young's modulus, adhesion, wettability, and surface free energy have been carried out. The ability to release silver ions from the surface of produced nanocomposite materials immersed in phosphate-buffered saline (PBS) solution has been estimated using inductively coupled plasma mass spectrometry (ICP-MS). The results of our studies proved the usefulness of the CVD method to enrich of the Ti6Al4V/TNT system with silver nanoparticles. Among the studied surface-modified titanium alloy implants, the better nano-mechanical properties were noticed for the Ti6Al4V/TNT/AgNPs composite in comparison to systems non-enriched by AgNPs. The location of silver nanoparticles inside of titania nanotubes caused their lowest release rate, which may indicate suitable properties on the above-mentioned type of the composite for the construction of implants with a long term antimicrobial activity.
\end{abstract}

Keywords: titanium alloy; silver nanoparticles; surface morphology; mechanical properties; surface free energy; silver ions release

\section{Introduction}

The design and the manufacture of customized implants using innovative technologies is one of the main directions in modern implantology development [1,2]. New generation implants fabrication besides their anatomic fit [3,4] requires the development of new alloys and composite coatings, which provide them suitable biointegration properties, but also improve their mechanical properties, durability, hydrophilicity, etc. The implant, in order to be effective, must not only restore the function of the organ, but also ensure the patient's comfort, and protect him from negative effects, e.g., formation of inflammation or allergic reactions. The customization of implants in the patient anatomy is associated with the development of the numeric image techniques and such three-dimensional (3D) printing 
technology as selective laser sintering (SLS) and selective laser melting (SLM). Both above-mentioned techniques allow for the formation of three-dimensional metal structures by selective melting of metal powder in a layer-by-layer manner, which enable the formation of products with new chemical properties, differing from their macroscopic equivalents [5-7]. The response of the tissues to the implant is largely controlled by the implant surface morphology and properties. When compared to smooth surfaces, textured implants surfaces exhibit larger surface area for integrating with bone, via osseointegration process. Improved bone bonding and accelerated bone formation appears to be possible with roughened surfaces that are modified with certain treatments, which can be classified into mechanical, physical, chemical, and electrochemical methods [8]. Our earlier works on the modification of titanium and Ti6Al4V implants have shown that the fabrication of $\mathrm{TiO}_{2}$ nanotube (TNT) layers of strictly defined tubes diameter on their surface had an impact on the cell adhesion and proliferation improvement $[9,10]$.

Another problem, which should be taken into account during the designing new generation of implants, is the appearance of complications after implant introduction-a possible bacterial infections. Infections that are related to foreign body are difficult to treat because the bacteria, which cause these infections, live in well-developed biofilms. In this way, there are protected against the action of antimicrobials [11,12]. The providing the antimicrobial activity of implant surface is a complicated issue due to the necessity of the antimicrobial coatings use, which should be universal versus different strains of bacteria that are present in the organism and/or introduced with the implant [13]. Surface-modified implants with a layer of titanium dioxide can be enriched with biocides: antibiotics or other antibacterial agents. Antibiotics can be used for this purpose, however, due to bacterial resistance and concerns about their long-term effectiveness, they may not produce the desired effects [14]. Silver is the most well known antimicrobial agent of low toxicity to mammalian cells and it is effective against more than 650 pathogens. According results of previous studies, it should be noted that AgNPs are one of the most viable alternatives to antibiotics and they may be used in a wide range of applications [15-20]. AgNPs can be synthesized using the sol-gel method, electrophoretic deposition from aqueous suspensions, physical vapor deposition (PVD), chemical vapor deposition (CVD), and atomic layer deposition (ALD) [21-24]. In our works, we have focused on the use of CVD methods, which allow the formation of dispersed AgNPs on the substrate surface. The shape, size, and dispersion level of silver nanoparticles can be controlled, by optimizing the deposition parameters and also by the type of chemical compound that is used as a precursor [25]. Silver(I) complexes with fluorinated or non-fluorinated $\beta$-diketonates/carboxylates and tertiary phosphines are the most commonly used as precursors in these techniques [26,27]. Also, the selected silver(I) carboxylates can be applied as a solid source of metallic particles in CVD techniques, within silver(I) pentafluoropropionate $\left(\mathrm{Ag}\left(\mathrm{O}_{2} \mathrm{CC}_{2} \mathrm{~F}_{5}\right)\right.$, as an example. The advantage of this compound is suitable volatility, low decomposition temperature at low vacuum, and a short deposition time. Moreover, it is characterized by simple and cheap synthesis [28]. In this paper, we present the results of the use of trihydrate of the above-mentioned compound as a new silver CVD precursor. The carried out studies concern the optimization of a CVD method for the production of dispersed AgNPs on the surface of Ti6Al4V implants that were manufactured by the SLS method, as obtained and modified by titanium dioxide nanotubes of different diameters. The important part of our works was the estimation of wettability, surface roughness, and mechanical properties of the produced implants. The results concerning the above-mentioned issues are not widely discussed in previous reports. Moreover, the silver ions releasing from the surface is discussed in the presented paper. It is especially important for the potential application of Ti6Al4V / AgNPs and T6Al4V/TNT/AgNPs composite materials in the construction of customized implants. 


\section{Results}

\subsection{The Chemical Vapor Deposition of Silver Nanoparticles}

\subsubsection{Precursor-The Structure and Thermal Properties of $\left[\mathrm{Ag}_{5}\left(\mathrm{O}_{2} \mathrm{CC}_{2} \mathrm{~F}_{5}\right)_{5}\left(\mathrm{H}_{2} \mathrm{O}\right)_{3}\right]$}

Simple and inexpensive synthesis of silver(I) pentafluoropropionate, and the especially suitable properties of this compound as a silver CVD precursor decided its choice for all of our experiments related to the enrichment of Ti6Al4V implants by AgNPs [28,29]. The purification of $\operatorname{Ag}\left(\mathrm{O}_{2} \mathrm{CC}_{2} \mathrm{~F}_{5}\right)$ by the slow recrystallization of this compound from anhydrous ethanol enabled obtaining the needle-like crystals, which quality did not allow for determining their structure on the base of single crystals x-ray diffractometry. The use of $1: 2 \mathrm{EtOH} / \mathrm{H}_{2} \mathrm{O}$ mixture in the recrystallization process allowed for the isolation of colorless crystals after five days. Their stability in air and light was higher than pure $\mathrm{Ag}\left(\mathrm{O}_{2} \mathrm{CC}_{2} \mathrm{~F}_{5}\right)$. Analysis of single crystal X-ray diffraction data exhibits the formation of $\mathrm{Ag}(\mathrm{I})$ complex of the formula $\left[\mathrm{Ag}_{5}\left(\mathrm{O}_{2} \mathrm{CC}_{2} \mathrm{~F}_{5}\right)_{5}\left(\mathrm{H}_{2} \mathrm{O}\right)_{3}\right]$, which crystallizes in the triclinic system, space group P-1 (Figure 1, Table 1).

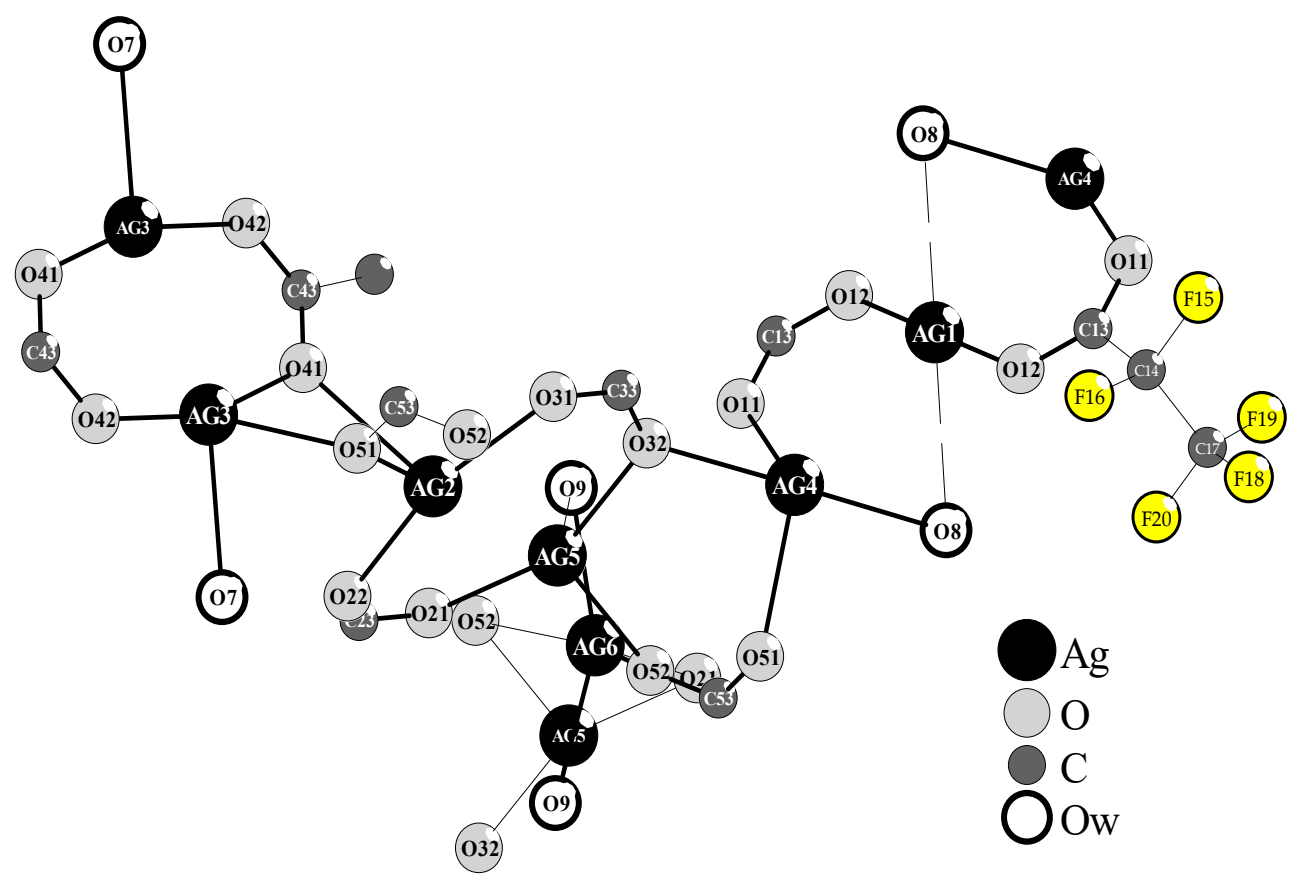

Figure 1. The scheme of the structure of $\left[\mathrm{Ag}_{5}\left(\mathrm{O}_{2} \mathrm{CC}_{2} \mathrm{~F}_{5}\right)_{5}\left(\mathrm{H}_{2} \mathrm{O}\right)_{3}\right]$. For clarity, the position of only one $\mathrm{C}_{2} \mathrm{~F}_{5}$ group has been presented (the full structure image is shown in the supplementary file: pp11a-2000-sch_shape-13b3-checkcif).

The structure of this complex is formed by five differently surrounded $\mathrm{Ag}(\mathrm{I})$ atoms, which are linked by carboxylate bridges and water molecules. However, the presence of three water molecules $\left(\mathrm{O}_{\mathrm{w}}=\mathrm{O} 7, \mathrm{O} 8, \mathrm{O} 9\right)$ in the structure of this $\mathrm{Ag}(\mathrm{I})$ compound influences on its novelty and thereby its use as a new silver CVD precursor. Analysis of the single crystal X-ray diffraction data revealed that $\mathrm{O} 7$ bridges Ag3 and Ag4 atoms, forming the metal-oxide bonds of lengths 2.547 and $2.426 \AA$ (Table 1). Simultaneously, O12-O7 and O22-O7 of 2.776 and $2.729 \AA$ suggest the formation of middle hydrogen bonds [30]. Whereas, O8 and O9 molecules are strongly bonded by Ag4 (2.577 $⿱$ ) and Ag6 (2.318 $\AA$ ) and they are in the field of interactions with Ag1 (2.825 $\AA$ ) and Ag5 (2.545 $\AA$ ) (Table 1). The $\mathrm{O}_{\mathrm{w}}-\mathrm{O}$ and $\mathrm{O}_{\mathrm{w}}-\mathrm{F}$ distances below 2.8-3.4 $\AA$, which were found between O42-O8-F70 (2.924 and $3.404 \AA$ ), O11-O9-F15 (2.777 and $3.051 \AA$ ) suggest the formation of middle and weak hydrogen bonds. 
Results of the thermal analysis (TG/DTG/DTA) revealed that the thermal decomposition of this compound proceeds in one step and it is an endothermic process (beginning $-453 \mathrm{~K}$, max $-598 \mathrm{~K}$, and ending - $613 \mathrm{~K})$.

Table 1. Selected bonds lengths $[\AA]$ and angles $\left[^{\circ}\right]$ for $\left[\mathrm{Ag}_{5}\left(\mathrm{O}_{2} \mathrm{CC}_{2} \mathrm{~F}_{5}\right)_{5}\left(\mathrm{H}_{2} \mathrm{O}\right)_{3}\right]$.

\begin{tabular}{|c|c|c|c|c|c|}
\hline Bond Length & & & & & \\
\hline Ag1-O12 & $2.138(5)$ & Ag3-O42 & $2.205(4)$ & Ag5-O21 & $2.234(5)$ \\
\hline $\operatorname{Ag} 1-\mathrm{O} 12^{\mathrm{i}}$ & $2.138(5)$ & Ag3-O41 & $2.218(4)$ & Ag5-O32 & $2.249(4)$ \\
\hline Ag1-O8 & $2.825(6)$ & Ag3-O7 & $2.547(4)$ & Ag5-O52 & $2.379(5)$ \\
\hline $\mathrm{Ag} 1-\mathrm{Ag} 4^{\mathrm{i}}$ & $3.0058(5)$ & Ag3-O51 & $2.588(4)$ & Ag5-O9 & $2.641(6)$ \\
\hline Ag1-Ag4 & $3.0058(5)$ & Ag3-Ag3 ${ }^{\mathrm{iii}}$ & $2.8932(9)$ & Ag5-Ag2 ii & $2.8951(7)$ \\
\hline Ag2-O31 ii & $2.219(5)$ & Ag4-O11 & $2.324(4)$ & Ag5-Ag6 & $3.239(2)$ \\
\hline Ag2-O22 & $2.237(5)$ & Ag4-O7 & $2.426(4)$ & Ag6-O9 & $2.318(7)$ \\
\hline Ag2-O51 & $2.553(4)$ & Ag4-O51 & $2.511(4)$ & Ag6-O9 iv & $2.412(8)$ \\
\hline Ag2-O41 & $2.610(4)$ & Ag4-O32 & $2.540(5)$ & Ag6-O52 iv & $2.472(6)$ \\
\hline $\mathrm{Ag} 2-\mathrm{Ag} 5 \mathrm{ii}$ & $2.8950(7)$ & Ag4-O8 & $2.577(6)$ & Ag6-O52 & $2.579(6)$ \\
\hline Ag2-Ag5 & $3.3236(8)$ & & & Ag6-O21 & $2.593(5)$ \\
\hline \multicolumn{6}{|l|}{ Angles } \\
\hline O12-Ag1-O12 ${ }^{i}$ & 180.0 & O42-Ag3-O41 & $162.69(16)$ & O21-Ag5-O32 & $155.4(2)$ \\
\hline O12-Ag1-Ag $4^{\mathrm{i}}$ & $95.09(12)$ & O42-Ag3-O7 & $91.16(14)$ & O21-Ag5-O52 & $93.4(2)$ \\
\hline $\mathrm{O} 12^{\mathrm{i}}-\mathrm{Ag} 1-\mathrm{Ag} 4^{\mathrm{i}}$ & $84.91(12)$ & O41-Ag3-O7 & $104.90(15)$ & O32-Ag5-O52 & $108.9(2)$ \\
\hline O12-Ag1-Ag4 & $84.91(12)$ & O42-Ag3-O51 & $106.76(16)$ & O21-Ag5-Ag2 ii & $82.41(13)$ \\
\hline $\mathrm{O} 12^{\mathrm{i}}-\mathrm{Ag} 1-\mathrm{Ag} 4$ & $95.09(12)$ & O41-Ag3-O51 & $84.01(16)$ & O32-Ag5-Ag2 ii & 81.11(12) \\
\hline $\mathrm{Ag} 4^{\mathrm{i}}-\mathrm{Ag} 1-\mathrm{Ag} 4$ & 180.0 & O7-Ag3-O51 & $75.23(13)$ & O52-Ag5-Ag2 ii & $156.0(2)$ \\
\hline $\mathrm{O} 31^{\mathrm{i}}-\mathrm{Ag} 2-\mathrm{O} 22$ & $159.63(18)$ & O42-Ag3-Ag3 ${ }^{\text {iii }}$ & $82.99(11)$ & O21-Ag5-Ag6 & $52.75(13)$ \\
\hline O31 i -Ag2-O51 & $91.49(16)$ & O41-Ag3-Ag3 iii & 79.70(11) & O32-Ag5-Ag6 & $136.00(13)$ \\
\hline O22-Ag2-O51 & $108.03(16)$ & O7-Ag3-Ag3 iii & $158.57(10)$ & O52-Ag5-Ag6 & 51.94(14) \\
\hline $\mathrm{O} 31^{\mathrm{i}}-\mathrm{Ag} 2-\mathrm{Ag} 5^{\mathrm{ii}}$ & $81.38(12)$ & O51-Ag3-Ag3 iii & $126.20(10)$ & Ag2 ${ }^{\text {ii-Ag5-Ag6 }}$ & $133.99(5)$ \\
\hline O22-Ag2-Ag5 ii & $78.26(13)$ & O11-Ag4-O7 & $153.99(15)$ & O21-Ag5-Ag2 & $134.02(15)$ \\
\hline O51-Ag2-Ag5 ii & $163.39(10)$ & O11-Ag4-O51 & $126.55(15)$ & O32-Ag5-Ag2 & $61.71(13)$ \\
\hline $\mathrm{O} 31$ ii -Ag2-Ag5 & $61.33(14)$ & O7-Ag4-O51 & $78.78(14)$ & O52-Ag5-Ag2 & $82.47(13)$ \\
\hline O22-Ag2-Ag5 & $120.51(13)$ & O11-Ag4-O32 & $88.59(16)$ & Ag2 ii-Ag5-Ag2 & $83.578(19)$ \\
\hline O51-Ag2-Ag5 & $67.06(10)$ & O7-Ag4-O32 & $100.33(14)$ & Ag6-Ag5-Ag2 & $133.31(6)$ \\
\hline \multirow[t]{15}{*}{ Ag5 ${ }^{\mathrm{ii}}$-Ag2-Ag5 } & $96.42(2)$ & O51-Ag4-O32 & $85.85(15)$ & O9-Ag6-O9 iv & $154.41(13)$ \\
\hline & & O11-Ag4-O8 & 93.10(17) & O9-Ag6-O52 iv & $98.8(3)$ \\
\hline & & O7-Ag4-O8 & 78.17(17) & O9 iv $-\mathrm{Ag} 6-\mathrm{O} 52^{\text {iv }}$ & $78.7(2)$ \\
\hline & & O51-Ag4-O8 & 93.07(17) & O9-Ag6-O52 & $78.3(2)$ \\
\hline & & O32-Ag4-O8 & $178.31(16)$ & O9 iv-Ag6-O52 & $93.6(2)$ \\
\hline & & O11-Ag4-Ag1 & $74.81(10)$ & O52 iv -Ag6-O52 & $156.09(11)$ \\
\hline & & O7-Ag4-Ag1 & $79.64(9)$ & O9-Ag6-O21 & $79.1(2)$ \\
\hline & & O51-Ag4-Ag1 & $148.61(10)$ & O9 iv-Ag6-O21 & $124.0(2)$ \\
\hline & & O32-Ag4-Ag1 & $120.40(11)$ & $\mathrm{O} 52^{\mathrm{iv}}-\mathrm{Ag} 6-\mathrm{O} 21$ & $122.1(2)$ \\
\hline & & O8-Ag4-Ag1 & $60.22(15)$ & O52-Ag6-O21 & 81.03(19) \\
\hline & & & & O9-Ag6-Ag5 & $53.70(16)$ \\
\hline & & & & O9 iv-Ag6-Ag5 & $134.01(17)$ \\
\hline & & & & $\mathrm{O} 52^{\mathrm{iv}}$-Ag6-Ag5 & 147.11(18) \\
\hline & & & & O52-Ag6-Ag5 & $46.58(12)$ \\
\hline & & & & O21-Ag6-Ag5 & $43.30(11)$ \\
\hline
\end{tabular}

\footnotetext{
${ }^{\mathrm{i}}-\mathrm{x},-\mathrm{y},-\mathrm{z} ;{ }^{\mathrm{ii}}-\mathrm{x},-\mathrm{y}-1,-\mathrm{z}-1$; iii $^{\mathrm{ii}} \mathrm{x}, \mathrm{-y},-\mathrm{z}-1$; $^{\text {iv }}-\mathrm{x}-1,-\mathrm{y}-1,-\mathrm{z}-1$.
}

The analysis of the TG curve revealed that during heating of $\left[\mathrm{Ag}_{5}\left(\mathrm{O}_{2} \mathrm{CC}_{2} \mathrm{~F}_{5}\right)_{5}\left(\mathrm{H}_{2} \mathrm{O}\right)_{3}\right]$ between 298 and $773 \mathrm{~K}$ under an inert atmosphere $\left(\mathrm{N}_{2}\right)$, the weight loss of the studied sample was c.a. $63.3 \%$. It suggested that the metallic silver was a final product of this compound pyrolysis. To assess the volatility of the isolated $\mathrm{Ag}(\mathrm{I})$ compound, the variable temperature IR (VTIR) and the mass spectrometry (MS EI) studies have been carried out. The use of the VTIR method allowed for the estimation of the thermal stability of isolated crystals in the temperature range 303-523 K. According to 
VTIR data, the dehydration of $\left[\mathrm{Ag}_{5}\left(\mathrm{O}_{2} \mathrm{CC}_{2} \mathrm{~F}_{5}\right)_{5}\left(\mathrm{H}_{2} \mathrm{O}\right)_{3}\right]$ (disappearance of bands at 3436 and $3669 \mathrm{~cm}^{-1}$ ) and the clear changes in the way of carboxyl groups interaction with $\mathrm{Ag}(\mathrm{I})$ ions (splitting of the $v_{\mathrm{as}}(\mathrm{COO})$ band) were found between 303 and $398 \mathrm{~K}$ (Figure 2). The further heating of the studied compound of up to $523 \mathrm{~K}$ led to the formation of the stable system, which consisted of dimeric species. It was confirmed by the appearance of a single $v_{\mathrm{as}}(\mathrm{COO})$ band at $1690 \mathrm{~cm}^{-1}$ [28].

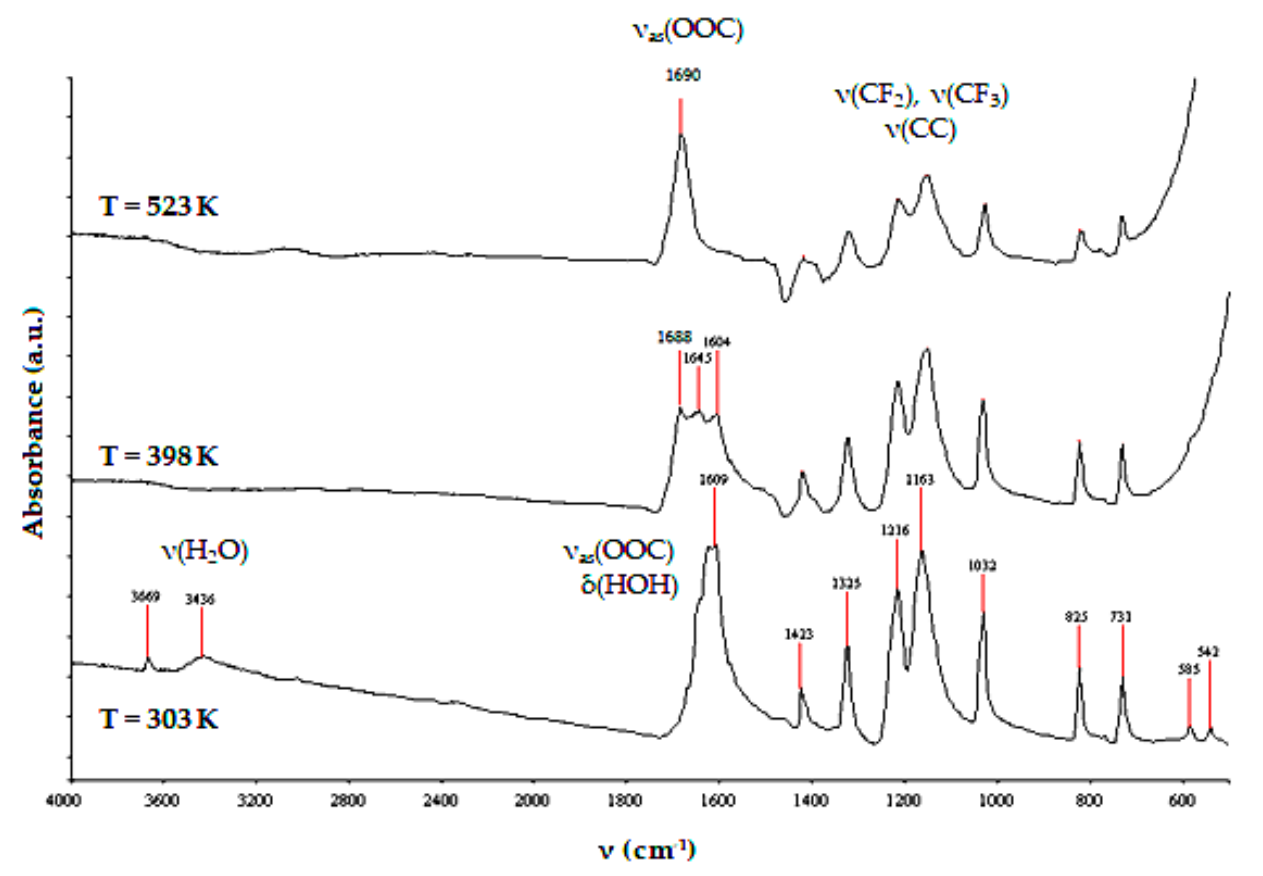

Figure 2. IR spectra of $\left[\mathrm{Ag}_{5}\left(\mathrm{O}_{2} \mathrm{CC}_{2} \mathrm{~F}_{5}\right)_{5}\left(\mathrm{H}_{2} \mathrm{O}\right)_{3}\right]$ registered at 303,398 , and $523 \mathrm{~K}$.

The use of mass spectrometry (MS EI) allowed for the determination of the vapor composition at temperatures 403 and $513 \mathrm{~K}$ during the heating of $\left[\mathrm{Ag}_{5}\left(\mathrm{O}_{2} \mathrm{CC}_{2} \mathrm{~F}_{5}\right)_{5}\left(\mathrm{H}_{2} \mathrm{O}\right)_{3}\right]$ (Table 2) [28,29]. Analysis of these data allowed for identifying the following silver(I) containing species: $\left[\mathrm{Ag}\left(\mathrm{O}_{2} \mathrm{CC}_{2} \mathrm{~F}_{5}\right)\left(\mathrm{H}_{2} \mathrm{O}\right)\right]^{+}$, $\left[\mathrm{Ag}\left(\mathrm{O}_{2} \mathrm{CC}_{2} \mathrm{~F}_{5}\right)_{2}\left(\mathrm{H}_{2} \mathrm{O}\right)\right]^{+},\left[\mathrm{Ag}_{2}\left(\mathrm{O}_{2} \mathrm{CC}_{2} \mathrm{~F}_{5}\right)_{3}(\mathrm{OC})\left(\mathrm{H}_{2} \mathrm{O}\right)\right]^{+}$, and $\left[\mathrm{Ag}_{2}\left(\mathrm{O}_{2} \mathrm{CC}_{2} \mathrm{~F}_{5}\right)_{3}(\mathrm{OOC})\left(\mathrm{H}_{2} \mathrm{O}\right)_{2}\right]^{+}$in the spectrum registered at $403 \mathrm{~K}$. It can indicate that dehydration process proceeds with the partial decomposition of trihydrate $\mathrm{Ag}(\mathrm{I})$ compound. The data presented in Table 2 suggest that the complete decomposition of this compound proceeds above $503 \mathrm{~K}$, and the following $\mathrm{Ag}(\mathrm{I})$ containing species will be transported in vapors: $\left[\mathrm{Ag}\left(\mathrm{C}_{2} \mathrm{~F}_{5}\right)\right]^{+},\left[\mathrm{Ag}_{2}\left(\mathrm{C}_{2} \mathrm{~F}_{5}\right)\right]^{+}$, and $\left[\mathrm{Ag}_{2}\left(\mathrm{O}_{2} \mathrm{CC}_{2} \mathrm{~F}_{5}\right)\right]^{+}$. Their appearance in vapors suggests that they can be the main source of the metallic silver in CVD processes.

\subsubsection{The Enrichment of Ti6Al4V and Ti6Al4V/TNT Substrates by Silver Nanoparticles (AgNPs)}

When considering the results of thermal decomposition and volatility studies of $\left[\mathrm{Ag}_{5}\left(\mathrm{O}_{2} \mathrm{CC}_{2} \mathrm{~F}_{5}\right)_{5}\right.$ $\left.\left(\mathrm{H}_{2} \mathrm{O}\right)_{3}\right]$, the overall conditions for carrying out the CVD processes were established. The optimal conditions have been determined during deposition experiments and the obtained results are listed in Table 3. The use of scanning electron microscopy (Scanning Electron Microscopy with Energy Dispersive Spectroscopy (SEM/EDS) method allowed for confirming that the result of the deposition processes were metallic silver nanoparticles (Figure 3). 
Table 2. Silver(I) fragmentation ions present on the mass spectra (MS EI) of $\left[\mathrm{Ag}_{5}\left(\mathrm{O}_{2} \mathrm{CC}_{2} \mathrm{~F}_{5}\right)_{5}\left(\mathrm{H}_{2} \mathrm{O}\right)_{3}\right]$ registered at 403 and $513 \mathrm{~K}$.

\begin{tabular}{|c|c|c|c|c|}
\hline Fragmentation Ions & $m / z$ & $403 \mathrm{~K}$ & $503 \mathrm{~K}$ & $523 \mathrm{~K}$ \\
\hline$[\mathrm{Ag}(\mathrm{CO})]^{+}$ & 136 & 8 & - & - \\
\hline$\left[\mathrm{Ag}\left(\mathrm{O}_{2} \mathrm{C}\right)\right]^{+}$ & 147 & 21 & 11 & 4 \\
\hline$\left[\mathrm{Ag}\left(\mathrm{O}_{2} \mathrm{CF}\right)\right]^{+}$ & 171 & 23 & $>2$ & - \\
\hline$\left[\mathrm{Ag}\left(\mathrm{C}_{2} \mathrm{~F}_{5}\right)\right]^{+}$ & 209 & 10 & 31 & 12 \\
\hline$\left[\mathrm{Ag}\left(\mathrm{O}_{2} \mathrm{CC}_{2} \mathrm{~F}_{5}\right)\left(\mathrm{H}_{2} \mathrm{O}\right)\right]^{+}$ & 289 & 100 & - & - \\
\hline$\left[\mathrm{Ag}_{2}\left(\mathrm{C}_{2} \mathrm{~F}_{5}\right)\right]^{+}$ & 335 & 58 & 100 & 38 \\
\hline$\left[\mathrm{Ag}_{2}\left(\mathrm{O}_{2} \mathrm{CC}_{2} \mathrm{~F}_{5}\right)\right]^{+}$ & 379 & - & 68 & 6 \\
\hline$\left[\mathrm{Ag}\left(\mathrm{O}_{2} \mathrm{CC}_{2} \mathrm{~F}_{5}\right)_{2}\left(\mathrm{H}_{2} \mathrm{O}\right)\right]^{+}$ & 452 & 10 & - & - \\
\hline$\left[\mathrm{Ag}_{2}\left(\mathrm{O}_{2} \mathrm{CC}_{2} \mathrm{~F}_{5}\right)\left(\mathrm{C}_{2} \mathrm{~F}_{5}\right)\right]^{+}$ & 498 & 30 & 5 & $>2$ \\
\hline$\left[\mathrm{Ag}_{2}\left(\mathrm{O}_{2} \mathrm{CC}_{2} \mathrm{~F}_{5}\right)_{2}(\mathrm{CO})\right]^{+}$ & 586 & $>2$ & $>1$ & - \\
\hline$\left[\mathrm{Ag}_{2}\left(\mathrm{O}_{2} \mathrm{CC}_{2} \mathrm{~F}_{5}\right)_{2}(\mathrm{CO})_{2}\right]^{+}$ & 598 & $>1$ & $>1$ & - \\
\hline$\left[\mathrm{Ag}_{3}\left(\mathrm{O}_{2} \mathrm{CC}_{2} \mathrm{~F}_{5}\right)\left(\mathrm{C}_{2} \mathrm{~F}_{5}\right)(\mathrm{CO})\right]^{+}$ & 635 & $>2$ & - & - \\
\hline$\left[\mathrm{Ag}_{3}\left(\mathrm{O}_{2} \mathrm{CC}_{2} \mathrm{~F}_{5}\right)_{2}(\mathrm{CO})\right]^{+}$ & 679 & $>1$ & - & - \\
\hline$\left[\mathrm{Ag}_{2}\left(\mathrm{O}_{2} \mathrm{CC}_{2} \mathrm{~F}_{5}\right)_{3}(\mathrm{OC})\left(\mathrm{H}_{2} \mathrm{O}\right)\right]^{+}$ & 752 & $>1$ & - & - \\
\hline$\left[\mathrm{Ag}_{2}\left(\mathrm{O}_{2} \mathrm{CC}_{2} \mathrm{~F}_{5}\right)_{3}(\mathrm{OOC})\left(\mathrm{H}_{2} \mathrm{O}\right)_{2}\right]^{+}$ & 784 & $>1$ & - & - \\
\hline
\end{tabular}

Table 3. Summary of chemical vapor deposition (CVD) conditions for the deposition of silver nanograins.

\begin{tabular}{ccc}
\hline & {$\left[\mathrm{Ag}_{5}\left(\mathbf{O}_{2} \mathbf{C C}_{2} \mathbf{F}_{5}\right)_{5}\left(\mathbf{H}_{2} \mathbf{O}\right)_{3}\right]$} & $\mathbf{A g}\left(\mathbf{O}_{2} \mathbf{C C}_{2} \mathbf{F}_{5}\right)[29]$ \\
\hline Total reactor pressure $(\mathrm{p})[\mathrm{hPa}]$ & $5 \times 10^{-1}$ & 4 \\
Substrate temperature $\left(\mathrm{T}_{\mathrm{D}}\right)[\mathrm{K}]$ & 553 & 563 \\
Vaporization temperature $\left(\mathrm{T}_{\mathrm{V}}\right)[\mathrm{K}]$ & 508 & 513 \\
Deposition rate $\left(r_{\mathrm{D}}\right)\left[\mathrm{mg} \cdot \mathrm{min}^{-1}\right]$ & $2.25-2.57$ & 2.56 \\
Carrier gas & $\mathrm{Ar}$ & $\mathrm{Ar}$ \\
Deposition time $[\mathrm{min}]$ & 30 & 30 \\
Precursor mass $[\mathrm{mg}]$ & 100 & 100 \\
\hline
\end{tabular}

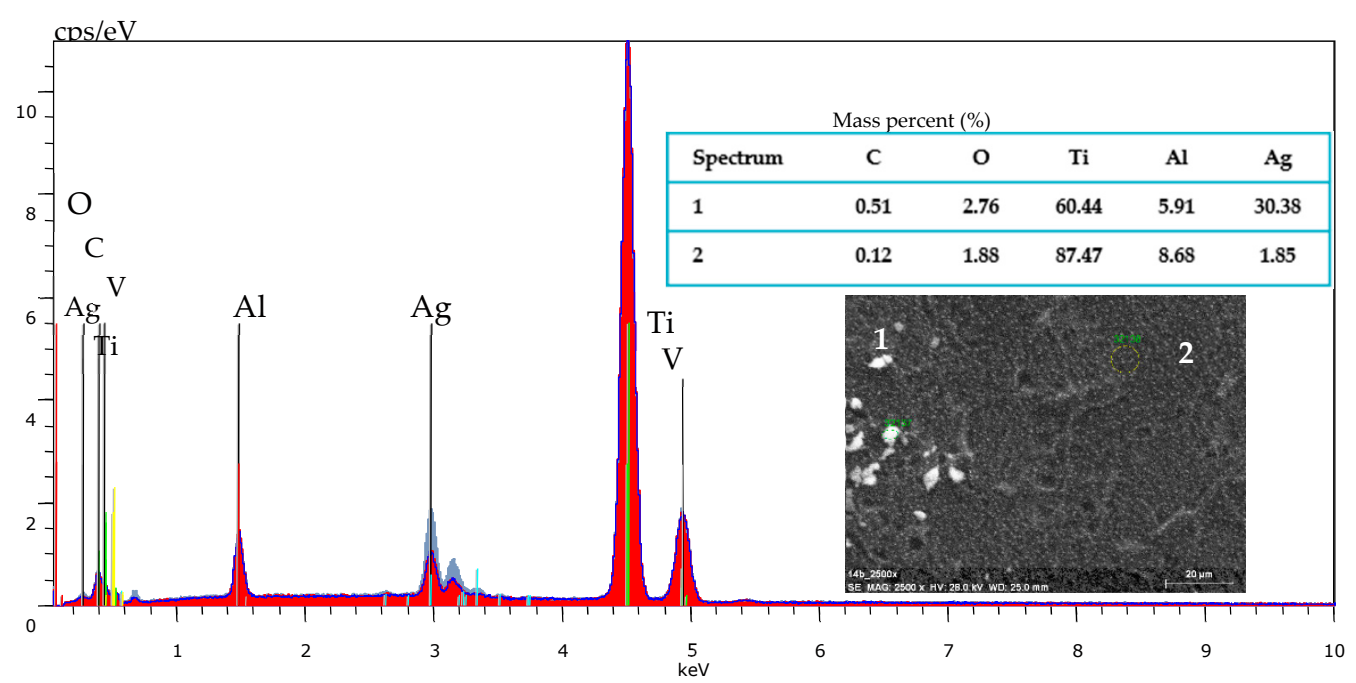

Figure 3. Energy Dispersive Spectroscopy (EDS) spectrum of Ti6Al4V/AgNPs sample and quantitative data.

Analysis of SEM images of the Ti6Al4V implant (Figure 4a) that were enriched by AgNPs revealed that the substrate surface is uniformly covered by Ag spherical grains of diameters from 15 up to $27 \mathrm{~nm}\left(r_{\mathrm{D}}=2.57 \mathrm{mg} \cdot \mathrm{min}^{-1}\right.$; Figure $\left.4 \mathrm{~b}\right)$. Ti6Al4V /TNT/AgNPs nanocomposites were produced during the two-step procedure. In the first step, the surface of Ti6Al4V implants (produced by the selective laser sintering (SLS) technique) was modified by titania nanotubes layer using the electrochemical anodization method. The anodization process was carried out using 5, 15, and $20 \mathrm{~V}$ potentials, 
and the obtained samples were designated as Ti6Al4V/TNT5, Ti6Al4V/TNT15, and Ti6Al4V/TNT20, respectively. The SEM images of the produced Ti6Al4V/TNT nanocomposites are presented in Figure 4c,e,g. According to these data, the produced TNT layers consisted of nanotubes of diameters ca. 35-45 nm (TNT5), 70-80 nm (TNT15), and 100-120 nm (TNT20). Analysis of Raman and DRIFT (diffuse reflectance infrared Furrier transformation) spectra proved the formation $\mathrm{TiO}_{2}$ amorphous layers.

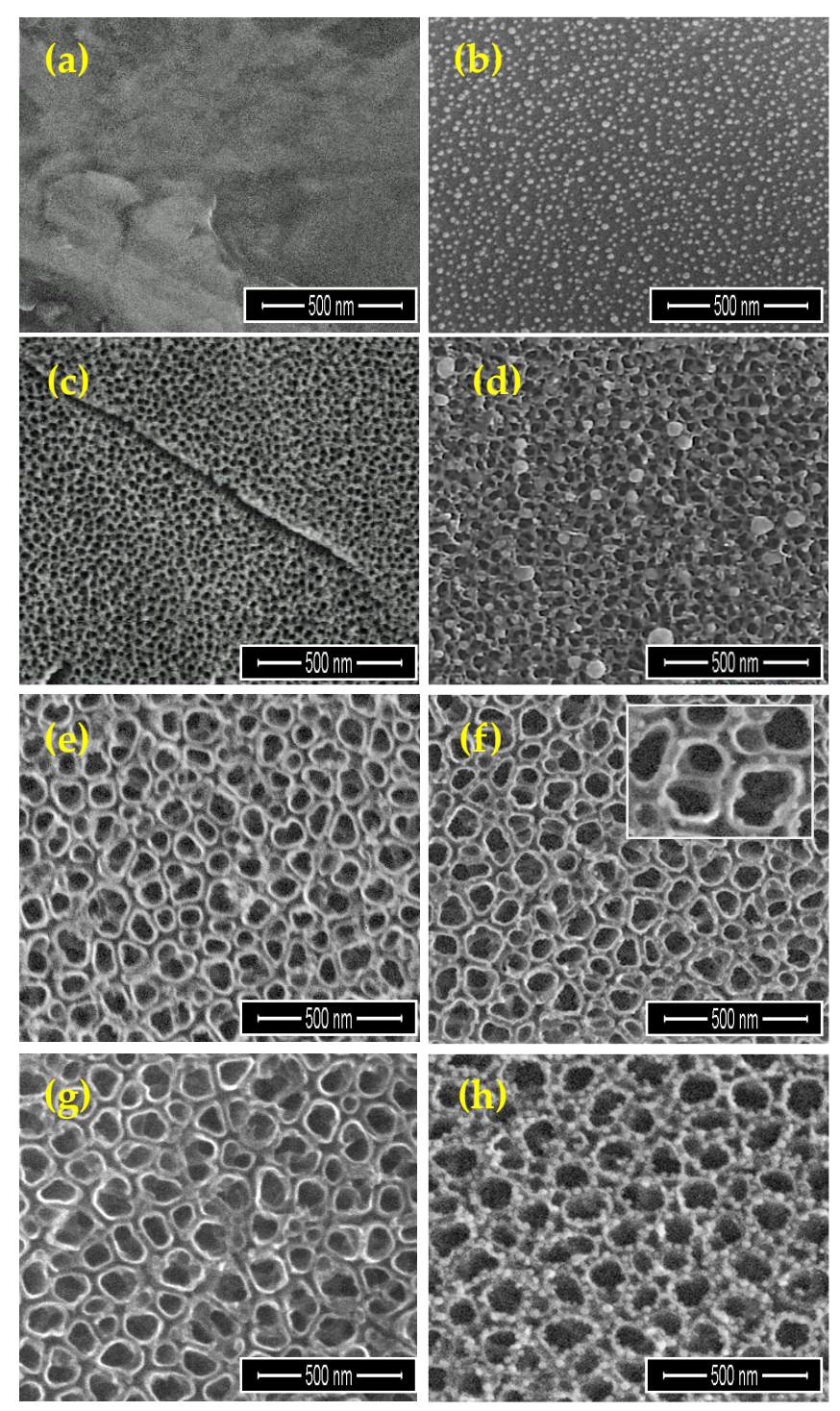

Figure 4. Scanning electron microscopy (SEM) images of Ti6Al4V (a), Ti6Al4V/AgNPs (b), Ti6Al4V/TNT5 (c), Ti6Al4V/TNT5/AgNPs (d), Ti6Al4V/TNT15 (e), Ti6Al4V/TNT15/AgNPs (f), Ti6Al4V/TNT20 (g), and Ti6Al4V/TNT20/AgNPs (h).

Enrichment of TNT layers by AgNPs using CVD technique was the next step. SEM images of modified titanium alloy implants are presented in Figure $4 \mathrm{~d}, \mathrm{f}, \mathrm{h}$. Dependently to the type of the TNT morphology layer, the differences in the size and distribution of AgNPs were noticed. Mass differences before and after CVD process of Ti6Al4V/TNT/AgNPs samples suggest the formation of coatings containing ca. $1.7 \mathrm{wt} \%$ (TNT5), $1.4 \mathrm{wt} \%$ (TNT15), and $1.9 \mathrm{wt} \%$ (TNT20) of silver grains. On the surface of Ti6Al4V / TNT5 coating, the dispersed nanoparticles of diameters 34-80 nm, were localized mainly on the layer surface $\left(r_{\mathrm{D}}=2.54 \mathrm{mg} \cdot \mathrm{min}^{-1}\right.$; Figure $\left.4 \mathrm{~d}\right)$. In the case of TNT15 coating, which consists of tubes of diameters 70-80 nm (TNT15) the size of AgNPs decreased up to 10-18 $\mathrm{nm}\left(r_{\mathrm{D}}=2.25 \mathrm{mg} \cdot \mathrm{min}^{-1}\right.$; Figure 4f). The deposited metallic grains were localized inside of tubes on their walls. A further increase in the nanotubes diameter (TNT20) was accompanied by an increase of the nanograins size up 
to $25-35 \mathrm{~nm}\left(r_{\mathrm{D}}=2.42 \mathrm{mg} \cdot \mathrm{min}^{-1}\right.$, Figure $\left.4 \mathrm{~h}\right)$. Also, in this case, AgNP were located on the surface of tube walls.

\subsection{Measurement of the Contact Angle and Surface Free Energy of Biomaterials}

Wettability of studied coatings surface and their surface free energy (SFE) were estimated using two different liquids, i.e., water as a polar liquid and diiodomethane as a dispersive one. In all studied cases, the values of contact angles, which were measured for water, were larger in comparison to adequate value for diiodomethane (Table 4). According to these data, the wettability of the Ti6Al4V/TNT surfaces increases in the row TNT5 < TNT15 < TNT20 (for TNT layers produced using potential of 5, 15, and 20V, respectively) and is better than for pure Ti6Al4V. The enrichment of these materials with AgNPs leads to the wettability decrease (increase of hydrophobic properties) and surface free energy decrease.

Table 4. The results of the contact angle measurement, which was made three times using distilled water and diiodomethane and the results of the surface free energy (SFE) of biomaterials used in Owens-Wendt method.

\begin{tabular}{cccc}
\hline \multirow{2}{*}{ Biomaterial Sample } & \multicolumn{2}{c}{ Average Contact Angle $\left[^{\circ}\right] \pm$ Standard Deviation } & \\
\cline { 2 - 2 } & \multicolumn{2}{c}{ Measuring Liquid } & SFE $\left[\mathbf{m J} / \mathbf{m}^{2}\right]$ \\
\cline { 2 - 3 } & Water & Diiodomethane & \\
\hline Ti6Al4V & $108.3 \pm 0.09$ & $37 \pm 0.16$ & $45.37 \pm 0.05$ \\
Ti6Al4V/AgNPs & $131.9 \pm 0.12$ & $89.6 \pm 0.50$ & $15.09 \pm 0.09$ \\
Ti6Al4V/TNT5 & $<10$ & $36 \pm 6.82$ & $>72.06$ \\
Ti6Al4V/TNT15 & $<10$ & $32.3 \pm 2.75$ & $>72.30$ \\
Ti6Al4V/TNT20 & $<10$ & $30.7 \pm 2.18$ & $>72.42$ \\
Ti6Al4V/TNT5/AgNPs & $124.2 \pm 0.06$ & $41.9 \pm 0.47$ & $51.97 \pm 0.15$ \\
Ti6Al4V/TNT15/AgNPs & $120.5 \pm 0.1$ & $67.3 \pm 0.96$ & $28.46 \pm 0.23$ \\
Ti6A14V/TNT20/AgNPs & $110.2 \pm 0.5$ & $72.3 \pm 0.73$ & $21.7 \pm 0.05$ \\
\hline
\end{tabular}

\subsection{Mechanical Properties of Ti6Al4V/AgNPs, Ti6Al4V/TNT, and Ti6Al4V/TNT/AgNPs}

The studies have been carried out for Ti6Al4V/AgNPs, Ti6Al4V/TNT, and Ti6Al4V/TNT/AgNPs systems, where TNT layers were produced using 5V (TNT5) and 15V (TNT15) potentials. The aim was to estimate mechanical property changes of two different types of TNT coatings that were enriched by AgNPs, i.e., the network formed by densely packed $\mathrm{TiO}_{2}$ tubes (TNT5) and the layer composed of separated and ordered nanotubes (TNT15).

\subsubsection{Surface Topography}

Surface topographies of the obtained coatings and the reference Ti alloy were examined by means of atomic force microscopy (AFM, NaniteAFM, Great Britain) in the $50 \times 50 \mu \mathrm{m}$ area. Surface roughness parameter $S_{a}$, was determined using software that is an integral part of the device. As demonstrated by the conducted research, electrochemical anodization increases the roughness parameter $S_{a}$ for both coatings that were produced at $5 \mathrm{~V}$ and $15 \mathrm{~V}$. For the coating that was obtained at a voltage of $5 \mathrm{~V}$, the increase in the $S_{a}$ parameter was almost threefold and for the coating obtained with $15 \mathrm{~V}$, more than five times. Also, the implantation of silver ions into electrochemically anodized coatings further increases the $S_{a}$ parameter. In the case of the Ti6Al4V/TNT5/AgNPs coating, the $S_{\text {a }}$ parameter increased by a further $32 \%$ and for the Ti6Al4V / TNT15/AgNPs coating by $9.3 \%$. The implantation of silver ions into the Ti6Al4V substrate causes a threefold increase in surface roughness, from $\mathrm{S}_{\mathrm{a}}=$ $0.027 \mu \mathrm{m}$ to $S_{a}=0.078 \mu \mathrm{m}$ (Figure 5). 


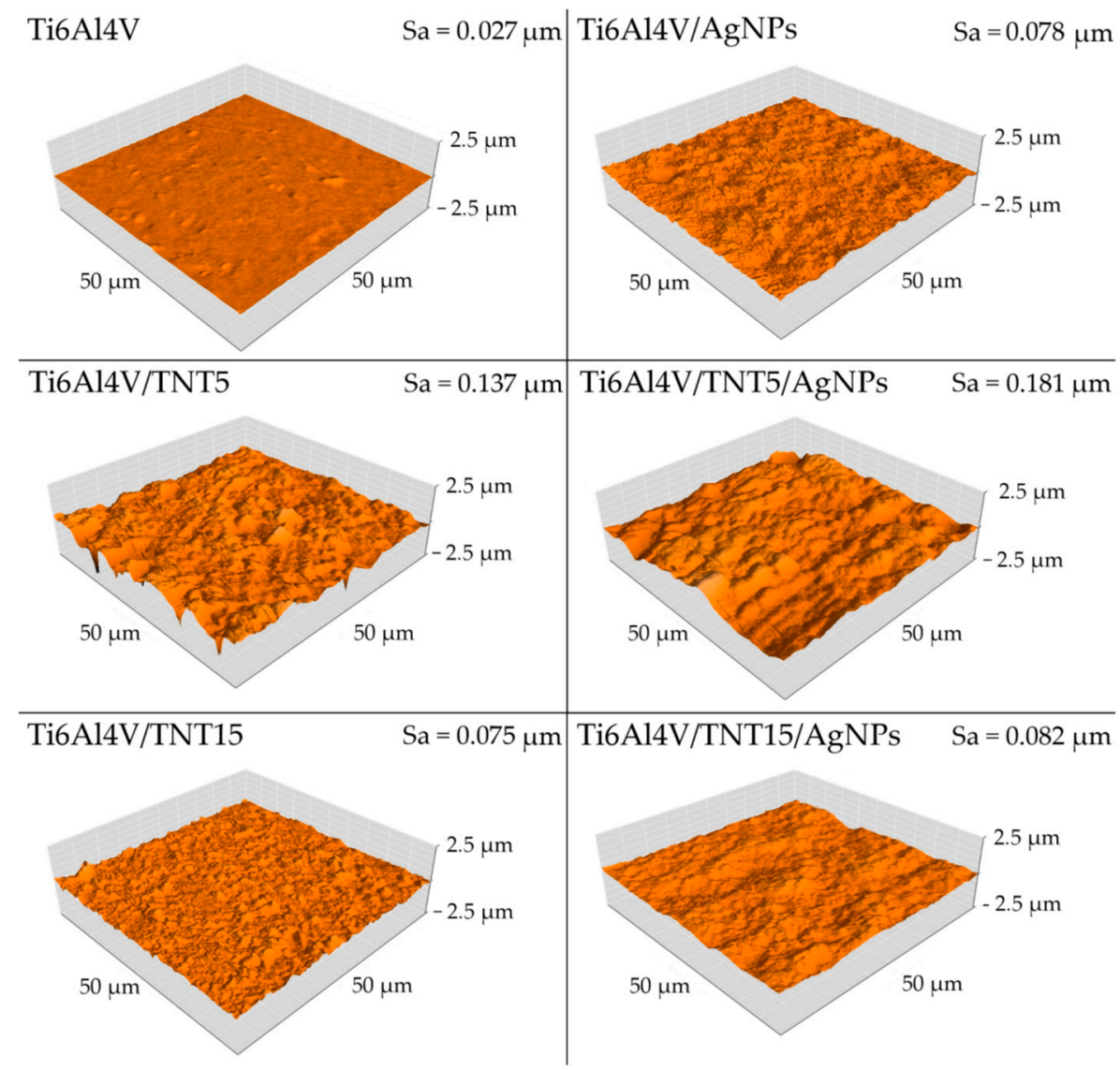

Figure 5. Atomic force microscopy (AFM) surface topography and $S_{a}$ parameter of reference Ti6Al4V, Ti6Al4V/AgNPs, and Ti6Al4V/TNT/AgNPs composites.

\subsubsection{Hardness and Young's Modulus}

Hardness tests were carried out using a Berkovich indenter. All of the tested samples were subjected to $25(5 \times 5)$ measurements of nanoindentation. Individual indentations were spaced $20 \mu \mathrm{m}$ apart (in both axes). Table 5 presents the mechanical properties measured in nanoindentation tests and Figure 6 exemplary hardness distribution on the area of $50 \times 50 \mu \mathrm{m}$. The obtained results revealed that the surface implantation of the Ti6Al4V alloy with silver ions causes a slight increase in hardness, from $6.18 \mathrm{GPa}$ to $6.81 \mathrm{GPa}$. On the other hand, after electrochemical anodization of the titanium alloy surface, the increase in hardness is greater than after surface implantation with silver ions. A particularly large, more than two and a half times, increase in hardness was noted for electrochemically anodized coatings that were obtained at $15 \mathrm{~V}$ (Ti6Al4V/TNT15).

Table 5. Mechanical properties (hardness, Young's Modulus and maximum depth of indentation) of reference Ti6Al4V, Ti6Al4V/AgNPs, and Ti6Al4V/TNT/AgNPs composites.

\begin{tabular}{cccc}
\hline Biomaterial Sample & Hardness [GPa] & Young's Modulus [GPa] & $\begin{array}{c}\text { Maximum Depth of } \\
\text { Indentation [nm] }\end{array}$ \\
\hline Ti6Al4V & $6.18 \pm 2.88$ & $230.12 \pm 21.68$ & $162.18 \pm 12.18$ \\
Ti6Al4V/AgNPs & $6.81 \pm 2.55$ & $187.54 \pm 54.33$ & $253.09 \pm 51.55$ \\
Ti6Al4V/TNT5 & $7.42 \pm 3.30$ & $229.71 \pm 88.07$ & $302.40 \pm 61.85$ \\
Ti6Al4V/TNT15 & $16.23 \pm 8.81$ & $350.64 \pm 157.57$ & $168.11 \pm 46.04$ \\
Ti6Al4V/TNT5/AgNPs & $9.86 \pm 4.61$ & $253.93 \pm 87.14$ & $211.53 \pm 56.38$ \\
Ti6A14V/TNT15/AgNPs & $13.60 \pm 7.24$ & $287.03 \pm 92.92$ & $184.46 \pm 40.60$ \\
\hline
\end{tabular}




\section{Ti6Al4V/TNT5}

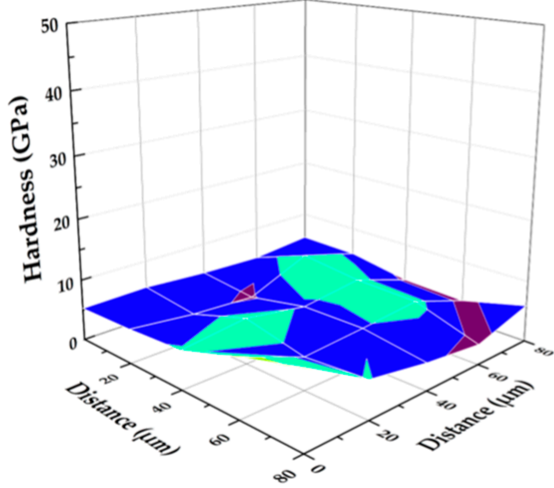

Ti6Al4V/TNT5/AgNPs

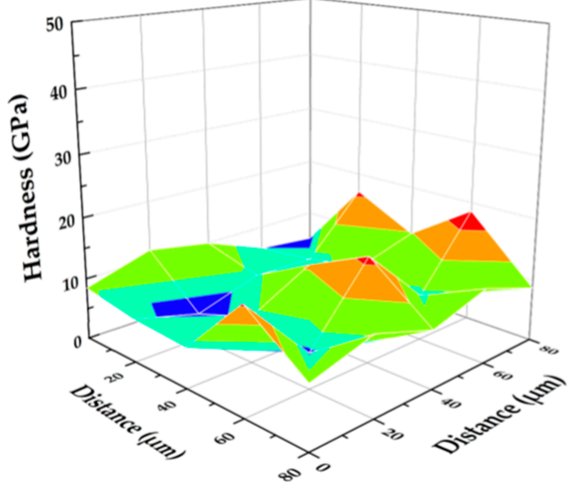

Ti6Al4V/TNT15

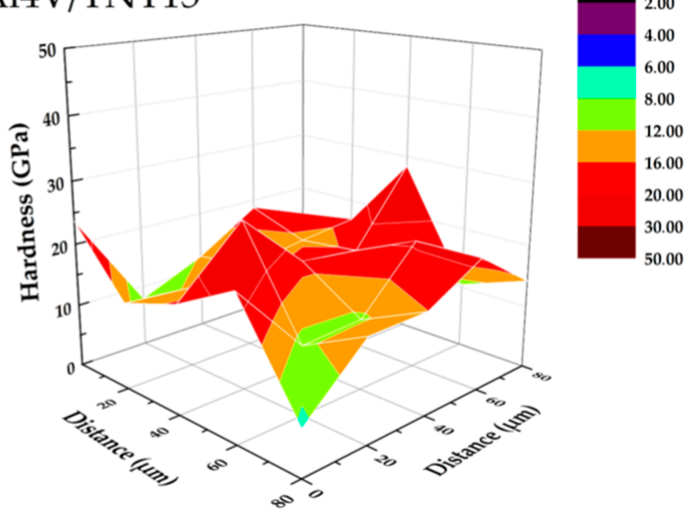

Ti6Al4V/TNT15/AgNPs

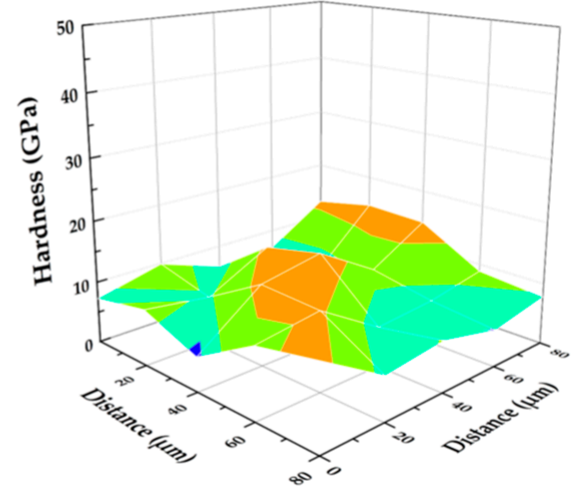

Figure 6. Hardness distribution of Ti6Al4V/TNT5, Ti6Al4V/TNT15, Ti6Al4V/TNT5/AgNPs, and Ti6Al4V/TNT15/AgNPs composites.

For coating obtained at $5 \mathrm{~V}$ (Ti6Al4V/TNT5), the increase in hardness was not so significant; the value only increased by $20 \%$. After implantation with silver ions electrochemically anodized coatings, it can be noticed that, depending on the anodizing voltage, the hardness either decreases or increases. In the case of anodized coating that was obtained at $5 \mathrm{~V}$, after implantation with silver ions an increase in hardness by $33 \%$ (from 7.42 GPa to $9.46 \mathrm{GPa}$ ) is observed. However, for anodized coating that was obtained at $15 \mathrm{~V}$, after implantation with silver ions, a $16 \%$ reduction in hardness is observed (from 16.23 GPa to 13.60 GPa). Similar changes after the silver ion implantation of anodized coatings, as in the case of hardness, can also be observed for the measured Young's modulus, i.e., an increase in stiffness for the Ti6Al4V/TNT5/AgNPs composite and a decrease in stiffness for the Ti6Al4V/TNT15/AgNPs composite. In turn, the implantation with silver ions of the surface of the Ti6Al4V alloy results in the reduction of the Young's modulus from $230.12 \mathrm{GPa}$ to $187.54 \mathrm{GPa}(18.5 \%)$.

\subsubsection{Adhesion Tests of Ti6Al4V/TNT and Ti6Al4V/TNT/AgNPs Composites}

The coatings were subjected to five scratch tests (individual nanosporks were spaced apart by $250 \mu \mathrm{m}$ ). Table 6 presents aggregate results for all investigated coatings and Figure 7 shows exemplary curves that were obtained in the scratch test. As can be seen from the data presented in Table 6, electrochemical anodization at 15 volts allows for obtaining coatings with greater adhesion to the substrate than anodizing at five volts. The critical force resulting in the loss of adhesion is about $39 \%$ higher for the coating obtained at 15 volts than for the coating obtained at five volts. 
Table 6. Results of nano scratch-tests of Ti6Al4V/TNT and Ti6Al4V/TNT/Ag composites.

\begin{tabular}{ccc}
\hline & \multicolumn{2}{c}{ Nano Scratch-Test Properties } \\
\hline Biomaterial Sample & Critical Friction $[\mathbf{m N}]$ & Critical Load $[\mathbf{m N}]$ \\
\hline Ti6Al4V/TNT5 & $155.76 \pm 69.02$ & $197.713 \pm 78.62$ \\
Ti6Al4V/TNT15 & $234.68 \pm 21.05$ & $275.03 \pm 28.91$ \\
Ti6Al4V/TNT5/AgNPs & $213.57 \pm 49.50$ & $275.11 \pm 58.15$ \\
Ti6Al4V/TNT15/AgNPs & $238.27 \pm 53.54$ & $267.74 \pm 75.73$ \\
\hline
\end{tabular}

\section{Ti6Al4V/TNT5}

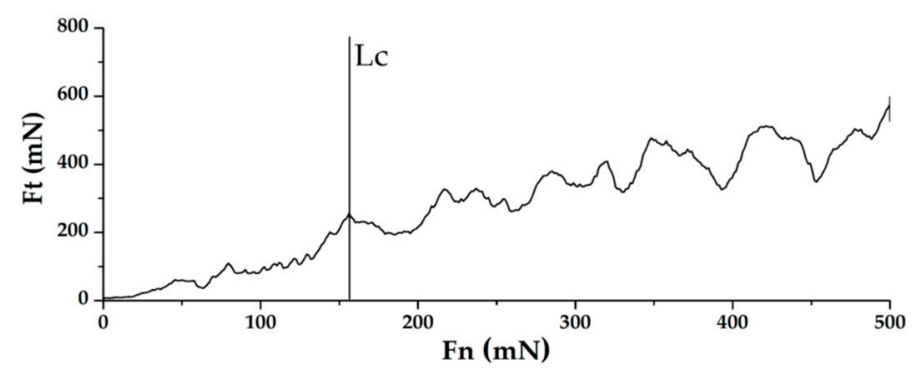

Ti6Al4V/TNT5/AgNPs

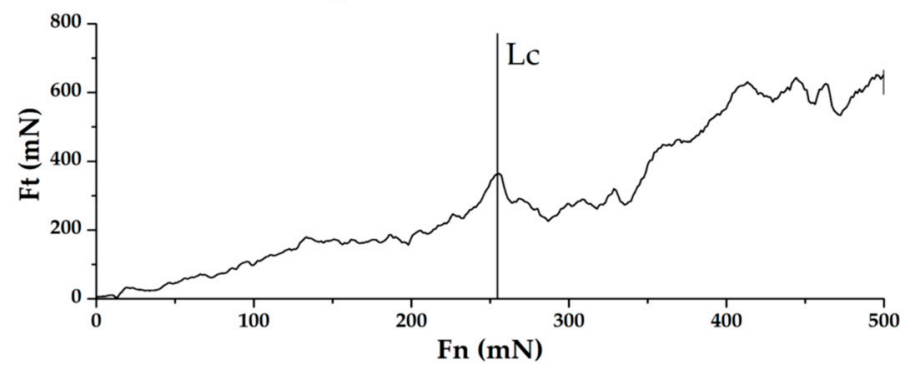

Figure 7. Examples of results obtained in the scratch test for Ti6Al4V/TNT5 coating and for Ti6Al4V/TNT5/AgNPs composite.

In addition, the standard deviation of the average results of the critical force causing the loss of adhesion to the substrate is about three times greater in the case of coatings that were obtained with the voltage of five volts. Implantation of electrochemically anodized coatings with Ag ions contributes to changes in the critical force that causes loss of coating adhesion. Electrochemically anodized coatings that were obtained at $5 \mathrm{~V}$, after their implantation with Ag ions, show an increase in critical force of about 39\%, while the implantation with Ag ions of coatings obtained at $15 \mathrm{~V}$ causes a slight decrease in adhesion by about $3.6 \%$.

\subsection{Evaluation of Stability and Durability of Coating Materials in the Body Fluid Environment}

The processes of silver ions releasing from the surface of Ti6Al4V / AgNPs and Ti6Al4V/TNT/ AgNPs samples, immersed in phosphate-buffered saline (PBS) solutions at human body temperature $(310 \mathrm{~K})$, were studied for five weeks. The results of these investigations are presented in Figure 8.

Analysis of inductively coupled plasma mass spectrometry (ICP-MS) data revealed that $3 \mathrm{~h}$ after immersion of Ti6Al4V / AgNPs system in the PBS solution, the concentration of $\mathrm{Ag}^{+}$ions was $0.18 \mathrm{ppm}$, and after 24 and $48 \mathrm{~h}$, it was 0.40 and $0.86 \mathrm{ppm}$, respectively (Figure 8; extracted graph). Over the next 12 days, a further increase in the concentration of $\mathrm{Ag}^{+}$in PBS solution was observed up to $2.52 \mathrm{ppm}$ after 14 days. 


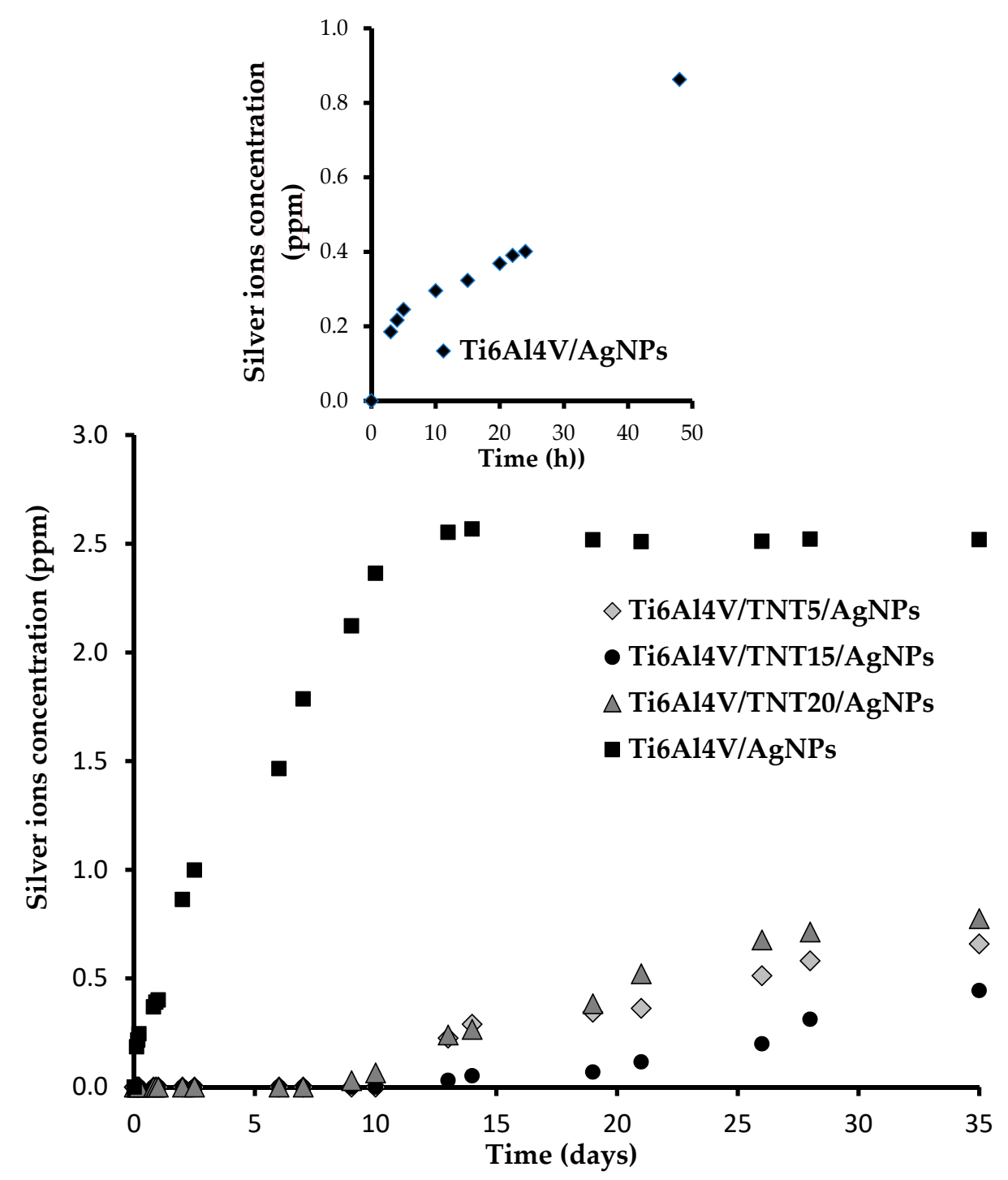

Figure 8. Silver ions released from Ti6Al4V/AgNPs coatings and Ti6Al4V/TNT5/AgNPs; Ti6Al4V/ TNT15/AgNPs; and, Ti6A14V/TNT20/AgNPs coatings immersed in phosphate buffered saline (PBS). The extracted graph shows the concentration changes of silver ions released from the surface of Ti6Al4V / AgNPs in the first $48 \mathrm{~h}$ after immersion off the sample in PBS solution.

During the next 14 days, the concentration of $\mathrm{Ag}^{+}$ions did not change significantly remaining at 2.51-2.57 ppm (Figure 8). Studies of Ti6Al4V/TNT/AgNPs composites, which were produced by the deposition of silver nanoparticles on the surface of titanium dioxide nanotubes, showed that the $\mathrm{Ag}^{+}$releasing processes were preceded in another way (Figure 8). In our experiments, we have used Ti6Al4V/TNT substrates of nanotube diameters ca. 35-45 nm (TNT5), 70-80 nm (TNT15), and 100-120 nm (TNT20). Obtained results revealed that during the first 14 days, the release of silver ions from the surface of all studied Ti6Al4V/TNT/AgNPs composites immersed in PBS solution, was not observed. After this time there was a slow increase of $\mathrm{Ag}^{+}$concentration, reaching the highest value ca. $0.77 \mathrm{ppm}$ (Ti6Al4V/TNT20/AgNPs) after 35 days, which was three times lower than in the case of the Ti6Al4V / AgNPs system (Figure 8). Simultaneously, the lowest concentration of $\mathrm{Ag}^{+}$, which amounted ca. $0.44 \mathrm{ppm}$ (after 35 days) has been noticed for Ti6Al4V/TNT15/AgNPs. The obtained results revealed the clear impact of AgNPs diameter and the manner of their arrangement on the surface of TNT layers on the concentration of released silver ions (Figure 4). 


\section{Discussion}

The implant samples that were fabricated by the selective laser sintering of Ti6Al4V powders (SLS technology) were used as substrates in all of our experiments, and the results are discussed in this paper. The appropriate porosity of substrates was obtained by covering their surface with $\mathrm{TiO}_{2}$ nanotube coatings (TNT), which were produced using the electrochemical anodization method [9,10,31]. In our works, we have focused on studies on amorphous Ti6Al4V/TNT systems that are produced using potentials: $5 \mathrm{~V}$ (Ti6Al4V/TNT5), $15 \mathrm{~V}$ (Ti6Al4V/TNT15), and $20 \mathrm{~V}$ (Ti6Al4V/TNT20), which showed the promising bioactivity [10]. The conversion of amorphous $\mathrm{TiO}_{2}$ layers into anatase phase during their heating up to $573 \mathrm{~K}$ were not noticed, which was confirmed by the analysis of IR and Raman spectra. This fact was important for our further works that are associated with the use of CVD technique in order to the enrichment of the Ti6Al4V and Ti6Al4V/TNT substrate surfaces with the AgNPs. Our earlier experience with the use of the different Ag(I) precursors in CVD experiments prompted us to choose $\mathrm{Ag}\left(\mathrm{O}_{2} \mathrm{CC}_{2} \mathrm{~F}_{5}\right)$ as a suitable source of dispersed AgNPs [28,29]. However, during the recrystallization of this compound from a 1:2 EtOH/ $\mathrm{H}_{2} \mathrm{O}$ mixture, the colorless crystals have been isolated after five days. The analysis of single crystals $\mathrm{X}$-ray diffraction data proved the formation of trihydrate species of the general formula $\left[\mathrm{Ag}_{5}\left(\mathrm{O}_{2} \mathrm{CC}_{2} \mathrm{~F}_{5}\right)_{5}\left(\mathrm{H}_{2} \mathrm{O}\right)_{3}\right]$ (Figure 1, Table 1). Three water molecules, which are presented in the structure of this compound (differently coordinated with silver atoms and taking part in possible interactions by hydrogen bonds with oxygen and fluorine atoms), should impact its properties as the CVD precursor. The results of volatility studies (VT IR and MS EI) showed that the heating of this compound in the range 303-503 K proceeded with its dehydration and the releasing of dimeric $\mathrm{Ag}(\mathrm{I})$ carboxylate species. Carried out studies exhibited that, in comparison to its anhydrous form, the isolated trihydrate crystals are characterized by the lower vaporization temperature at the pressure $5 \times 10^{-1} \mathrm{hPa}$. Moreover, CVD experiments proved that the deposition of dispersed AgNPs proceeded with the lower deposition rate $r_{\mathrm{D}}=2.25-2.57 \mathrm{mg} \cdot \mathrm{min}^{-1}$ at $T_{\mathrm{D}}=553 \mathrm{~K}$ (Table 3 ). The SEM images that are presented in Figure 4 indicated that spherical nanoparticles of silver of dimeters ca. 34-80 and 24-35 nm were localized on the surface of Ti6Al4V/TNT5/AgNPs and Ti6Al4V/TNT20/AgNPs coatings, respectively. Simultaneously, in the case of Ti6Al4V/TNT15/AgNPs, most of silver particles were localized on the walls, inside of tubes. The differences that are mentioned above can explain the noticed changes in wettability (hydrophilicity) and in the way of silver ions releasing from Ti6Al4V/TNT/AgNPs composites.

The direct consequence of the TNT layer formation on the surface of Ti6Al4V implant is the surface wettability increase with simultaneous surface free energy growth (Table 4). The obtained results are in good accordance with previous reports [32]. The enrichment of Ti6Al4V and Ti6Al4V/TNT surface by AgNPs lead to a decrease of their wettability and SFE value. The analysis of water contact angle changes revealed that the AgNPs deposition on the surface of hydrophilic surface of TNT coatings (water contact angle $<10 \mathrm{deg}$ ) lead to the increase of their hydrophobicity (water contact angle was changed to 110.2-124.2 deg) (Table 4). Simultaneously, it should be noted that hydrophobicity of studied samples decreases in the row: Ti6Al4V/TNT5/AgNPs > Ti6Al4V/TNT15/AgNPs > Ti6A14V/TNT20/AgNPs. This effect can be related to the increase of nanotubes diameter from 35-45 nm up to 100-120 nm, and thus a higher ability to penetrate the interior of the nanotubes by the liquid. The increase of hydrophobicity of TNT layers (diameter $33 \mathrm{~nm}$ ) after their decoration by AgNPs (diameter $35 \mathrm{~nm}$ ) was also noticed by Caihong et al. [33]. The insertion of an AgNPs-enriched implant into an aqueous solution is associated with the oxidation of metal nanoparticles and the releasing of silver ions, which has direct impact on potential antimicrobial properties of the produced coatings [34]. Figure 8 shows that $\mathrm{Ag}^{+}$ions were released with the high rate in the first 12 days from the surface of Ti6Al4V/AgNPs system. After this time, the release rate changes indicate saturated behavior, and the concentration of the $\mathrm{Ag}^{+}$ions in PBS was close to $2.5 \mathrm{ppm}$. The higher concentration of these ions than 10 ppm in the human body can be toxic [35]. Zaho et al. showed a similar way of $\mathrm{Ag}^{+}$releasing from the surface of Ti/AgNPs substrates, however the concentration of silver ions in PBS solution after seven days stabilized on the level 0.13 ppm [36]. In the case of Ti6Al4V/TNT/AgNPs coatings that 
are immersed in PBS solution, the different silver ion releasing pathway has been noticed (Figure 8). Independently to the TNT diameters (TNT5-35-45 nm, TNT15-70-80 nm, TNT20-100-120 nm), the silver ions release process was not observed in first seven days. After this time, the $\mathrm{Ag}^{+}$ions concentration slowly increases, reaching values $0.44-0.77 \mathrm{ppm}$ after 35 days dependently to the TNT diameter, AgNPs size, and the way of their distribution. Attention is drawn to the fact that the release rate of silver ions from Ti6Al4V/TNT20/AgNPs (lowest value of SFE and water contact angle $110.2 \mathrm{deg}$ ) is higher in comparison to Ti6Al4V/TNT15/AgNPs (highest value of SFE and water contact angle $124.2 \mathrm{deg}$ ) (Table 4). The earlier studies of Ti/TNT(anatase)/ AgNPs composites (tube diameters were 50,75 , and $100 \mathrm{~nm}$ ) revealed that $\mathrm{Ag}^{+}$ions were releasing with the high rate in the first two days and maintaining concentration at the level $0.25-0.28 \mathrm{ppm}$ [36]. Also, in this case, the highest release rate was noticed for AgNPs that were deposited on the surface of TNT layer consisted from tubes of diameter $100 \mathrm{~nm}$. Our earlier studies of $\mathrm{Ag}^{+}$ions releasing from Ti/TNT/AgNPs composites revealed that, after 21 days, the concentrations of these ions in PBS solution were close to $0.005-0.008 \mathrm{ppm}$, and after 28 days they increased to the level 0.15-0.22 ppm [9].

$\mathrm{Up}$ till now, the mechanical properties of $\mathrm{TiO}_{2}$ coatings that are produced by the electrochemical anodization of titanium alloys have been poorly explored. However, Young's modulus, hardness, and adhesion of the coating to the substrate can be the decisive factors in terms of applications, for example, when considering the production of such coatings on implants elements. The strong integration of an implant with the bone tissue is crucial for the safe operation of the implant. The loss of coherence between the bone and the implant due to friction contributes to the implant wear. The abrasive wear of the implant may additionally cause inflammatory reactions in the patient's body. Von Wilmowsky et.al reported in their work [37] that $\mathrm{TiO}_{2}$ nanotube coatings have shown a "good" qualitative adherence, but other reports $[38,39]$ have qualified such coatings as "not very well adherent". The results of our nano scratch-tests revealed that the adhesion of the Ti6Al4V/TNT15 coating to the substrate is slightly greater than the Ti6Al4V/TNT5 coating (Figure 7). This difference can be result in differences in the way of TNT coatings architecture. The TNT5 layer is composed of dense packed nanotubes of diameter ca. $35-45 \mathrm{~nm}$ and wall thicknesses ca. $12 \mathrm{~nm}$, while the TNT15 consists of separated tubes of diameter ca. 70-80 nm and wall thicknesses ca. $20 \mathrm{~nm}$. After the AgNPs deposition on the surface of TNT5 coating, the dispersed nanoparticles with diameters of 34-80 nm were located mainly on the layer surface, which should not impact the adhesion of the coating to the substrate. However, AgNPs of diameters that are similar to tube sizes can be located inside of tubes or close them. This can explain the adhesion increase of TNT5 coating from $197.7 \mathrm{mN}$ up to $275.03 \mathrm{mN}$ after the deposition AgNPs on its surface. In the case of TNT15 coating, which consists of tubes of diameters 70-80 nm (TNT15), the size of AgNPs decreased to 10-18 nm maximum. The metallic grains were located inside the tubes on their walls, which caused a slight decrease in the adhesion of the coating to the substrate (from $275.1 \mathrm{mN}$ to $267.7 \mathrm{mN}$ ).

Analysis of data presented in Table 5 revealed a clear increase of nano-mechanical properties (hardness, Young's modulus) of Ti6Al4V substrate surface after the formation Ti6Al4V/TNT system. However, it should be noted that the magnitude of these changes is associated with the morphology of the produced TNT coatings. The results of our measurements indicate that the hardness (7.42 GPa) and Young's modulus (229.71 GPa) of Ti6Al4V/TNT5 coatings are significantly lower than that of Ti6Al4V/TNT15 coatings (hardness 16.23 GPa and Young modulus $350.64 \mathrm{GPa}$ ), despite the fact that they have a finer nanotubes structure. It can be explained by the increase of both stiffness and hardness of coatings, which results from an increase of the used voltage in the anodization process. The earlier works revealed that voltage increase (at a constant process time) is accompanied with an increase nanotubes diameter, wall thickness, and also their length [40]. Moreover, the increase in voltage is accompanied by the growth of barrier layer thickness in the lower part of the nanotube, which results in the formation of larger pores and greater distance between them [41]. As a result of these processes, the nanotubes of larger diameter and wall thickness are formed. Bauer et al. [42], revealed that the anodizing of titanium using voltages $10-25 \mathrm{~V}$ led to the formation of coatings that are 
composed of separated and ordered nanotubes, while the use of lower voltages led to the formation of a structure resembling an ordered network. For studied coatings, the above-mentioned morphology changes were noticed for TNT5 and TNT15 respectively. Simultaneously, the values of the surface roughness decreased from $S_{a}=0.137 \mu \mathrm{m}$ for Ti6Al4V $/$ TNT5 to $S_{a}=0.075 \mu \mathrm{m}$ for Ti6Al4V /TNT15. The phase structure of nanotubes is the next important factor that can influence the hardness and stiffness of TNT coatings. Analysis of the previous reports showed that anodized $\mathrm{TiO}_{2}$ nanotubes are amorphous in nature [43-45]. However, the method and parameters of coatings production as well as their heat treatment may affect the occurrence of crystalline $\mathrm{TiO}_{2}$ phases, such as anatase, rutile, or a mixture of these polycrystalline forms. It was indicated that amorphous $\mathrm{TiO}_{2}$ nanotubes are softer than mixture of amorphous and crystallized $\mathrm{TiO}_{2}$ (anatase) nanotubes. Also, the geometry of nanotubes, i.e., their length and wall thickness will affect the hardness measurement result [46-48]. In addition, it is well-known that the radius of the nanoindenter's tip rounding has an effect on the test results. The porosity of the coatings constitutes an additional parameter affecting their nano-mechanical properties. Munirathinam and Neelakantan reported [49] that porosity has a significant influence on the elastic modulus of the nanotubes. In our experiments, the potential of $15 \mathrm{~V}$ applied during the anodizing of the Ti6Al4V alloy was low enough for the formation of a structure with low porosity, as evidenced by the high Young's modulus of the Ti6Al4V/TNT15 coating. After enriching produced coatings by AgNPs, the hardness of the Ti6Al4V/TNT5 coating increased from 7.42 GPa to $9.86 \mathrm{GPa}$, while for the Ti6Al4V / TNT15 coating, the hardness decreased from 16.23 GPa to $13.60 \mathrm{GPa}$. In both cases, the values of $S_{a}$ parameters also increased (Figure 5). When considering that during the CVD process, the amorphousness of TNT coatings does not change, the increase of hardness and the roughness (from $S_{a}=0.137 \mu \mathrm{m}$ up to $S_{a}=0.181 \mu \mathrm{m}$ ) of the Ti6Al4V /TNT5/AgNPs composite can be explained by the deposition of AgNPs on the surface of an ordered network, which consists of the densely packed $\mathrm{TiO}_{2}$ nanotubes. In the case of Ti6Al4V/TNT15/AgNPs, the increase of tubes diameter $(70-80 \mathrm{~nm})$ and the deposition of silver nanoparticles in their interior slightly increase the coating roughness $\left(S_{a}=0.082 \mu \mathrm{m}\right)$, but its hardness decreases in comparison to the layer, which consists of separated and ordered $\mathrm{TiO}_{2}$ nanotubes.

\section{Materials and Methods}

\subsection{Synthesis of Silver CVD Precursor and Conditions CVD Processes Carry Out}

The silver(I) pentafluoropropionate has been synthesized according to previously reported procedure $[28,29]$. The slow recrystallization of this salt from the $1: 2 \mathrm{EtOH} / \mathrm{H}_{2} \mathrm{O}$ solution led to the isolation of stable in air and colorless crystals after five days. The light sensitivity of these crystals required their storage in the light protected container.

Yield: $89.2 \%$; anal. calculated for $\mathrm{C}_{10} \mathrm{H}_{6} \mathrm{~F}_{25} \mathrm{O}_{13} \mathrm{Ag}_{5}$ : C, 8.98\%, $\mathrm{H}, 0.44 \%$; Found: $\mathrm{C}, 9.09 \%, \mathrm{H}, 0.47 \%$. ${ }^{13} \mathrm{C}$ NMR $(75 \mathrm{MHz}), \delta(\mathrm{ppm}): 59.04\left(\mathrm{CF}_{2}\right), 117.49\left(\mathrm{CF}_{3}\right), 167.25(\mathrm{COO}),{ }^{19} \mathrm{~F} \mathrm{NMR}\left(\mathrm{CDCl}_{3}, 376 \mathrm{MHz}\right)$, $\delta(\mathrm{ppm}):-82.91(\mathrm{~s}, 3 \mathrm{~F}),-118.38(\mathrm{~d}, J=21.1 \mathrm{~Hz}, 2 \mathrm{~F})$ Solid NMR spectra were recorded in a Varian Gemini $200 \mathrm{MHz}$ NMR spectrometer in $\mathrm{CDCl}_{3}$ (Varian Inc., Palo Alto, CA, USA). Single crystal X-ray diffraction data were collected from a crystal of dimensions $0.57 \times 0.51 \times 0.38 \mathrm{~nm}$ with an Oxford Diffraction KM4 CCD diffractometer (Oxford Diffraction Ltd., Abingdon, Oxfordshire, UK) (Mo K $\alpha$ about wavelength $\lambda=0.71073 \AA$ ). The structure was solved by direct methods and it was refined with the full-matrix least squares on $\mathrm{F}^{2}$ using the software package SHELX-97 [50]. All of the figures were prepared in DIAMOND [51] and ORTEP-3 [52]. CCDC: 1477237; contains the supplementary crystallographic data for $\left[\mathrm{Ag}_{5}\left(\mathrm{O}_{2} \mathrm{CC}_{2} \mathrm{~F}_{5}\right)_{5}\left(\mathrm{H}_{2} \mathrm{O}\right)_{3}\right]$. These data can be obtained free of charge via http: / / www.ccdc.cam.ac.uk/conts/retrieving.html, or from the Cambridge Crystallographic Data Centre, 12 Union Road, Cambridge CB2 1EZ, UK; fax: (+44)1223-336-033; or e-mail: deposit@ccdc.cam.ac.uk. Crystal data and structure refinement for this compound are given in Table 7. 
Table 7. Crystal data and structure refinement for $\left.\left[\mathrm{Ag}_{5}\left(\mathrm{O}_{2} \mathrm{CC}_{2} \mathrm{~F}_{5}\right)_{5}\left(\mathrm{H}_{2} \mathrm{O}\right)_{3}\right)\right]$.

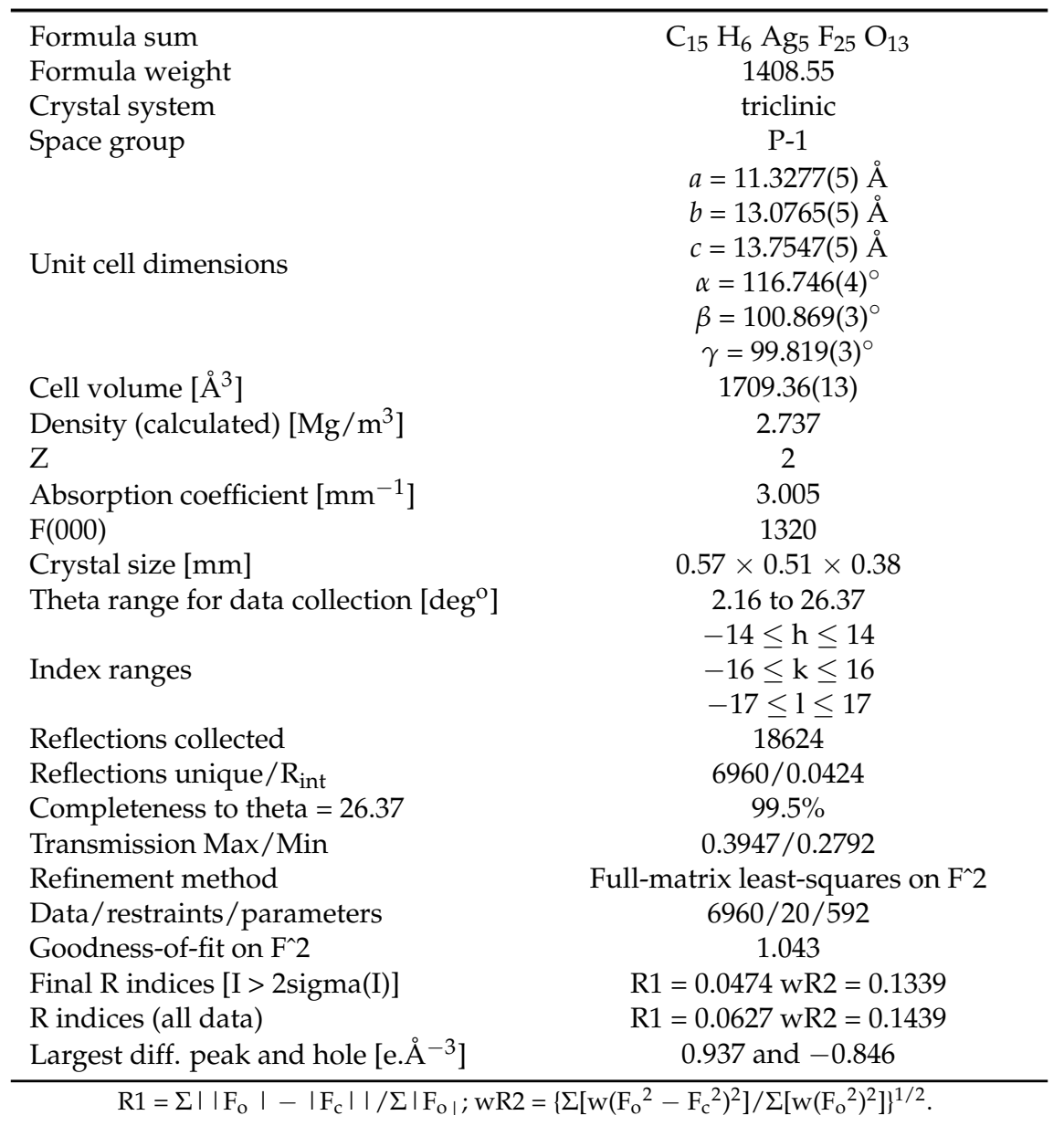

The enrichment of AgNPs on the surface of Ti6Al4V and Ti6Al4V/TNT substrates were carried out while using CVD method (the horizontal hot-wall reactor) under the conditions that are presented in Table 2 [29].

\subsection{The Production of Ti6Al4V/TNT Substrates and Its Characteristics}

Titanium dioxide nanotube layers (TNTs) were fabricated on the surface of implants of the radial bone (total area implant $-20.53 \mathrm{~cm}^{2}$, formed by selective laser sintering (SLS) of Ti6Al4V powder) as a result of the electrochemical anodic oxidation, according to the method previously described $[9,10,31]$. This process was carried out at the following voltages: $5 \mathrm{~V}$ (TNT5), $15 \mathrm{~V}$ (TNT15), and $20 \mathrm{~V}$ (TNT20). The anodizing time was $\mathrm{t}=30 \mathrm{~min}$. The morphology of the produced coatings was examined using a Quanta scanning electron microscope with field emission (SEM, Quanta 3D FEG, Huston USA). The structure of the produced $\mathrm{TiO}_{2}$ nanotube layers was studied while using Raman spectroscopy (RamanMicro 200 PerkinElmer (PerkinElmer Inc., Waltham, MA, USA) $(\lambda=785 \mathrm{~nm})$ ) and diffuse reflectance infrared Fourier transform spectroscopy (DRIFT, Spectrum2000, PerkinElmer Inc., Waltham, MA, USA).

\subsection{Measurement of the Contact Angle and Surface Free Energy of Biomaterials}

Determination of the wettability was carried out by the measuring of the contact angle. The contact

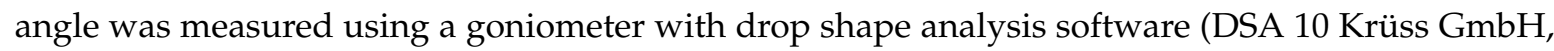
Hamburg, Germany). The liquids that were selected for measuring the contact angle were distilled water $\left(\mathrm{H}_{2} \mathrm{O}\right)$ and diiodomethane $\left(\mathrm{CH}_{2} \mathrm{I}_{2}\right)$. In the case of distilled water, the volume of the drop in the 
contact angle measurement was $3 \mu \mathrm{L}$, and in the case of diiodomethane $4 \mu \mathrm{L}$. The measurement of the contact angle was carried out immediately after deposition of the drop. In order to determine the surface free energy, mathematical calculations were performed using the Owens-Wendt method. Each measurement was carried out three times.

\subsection{Topographies and Mechanical Properties of the Produced Nanocoatings on the Surface of 3D Printed Implants}

Surface topographies were examined by means of atomic force microscopy (AFM, NaniteAFM, Nanosurf AG, Liestal, Switzerland) using a contactless module with a force of $55 \mathrm{mN}$ in the $50 \times 50 \mu \mathrm{m}$ area. Hardness tests and Young modulus measurements were carried out using a nanoindenter (NanoTest Vantage, Micro Materials Ltd., Wrexham, UK) using a pyramidal, diamond, three-sided Berkovich indenter, with an apical angle of $124.4^{\circ}$. Hardness tests were performed for the loads of $10 \mathrm{mN}$. The time of load increase from the zero value to the maximum load $10 \mathrm{mN}$ was $15 \mathrm{~s}$. Indentation involving one cycle with $5 \mathrm{~s}$ dwell at maximum load. Hardness values $(\mathrm{H})$, reduced Young's modulus (Er), and Young's modulus were determined using the Oliver-Pharr method using the NanoTest results analysis program. In order to convert the reduced Young's modulus into the Young's modulus, a Poisson coefficient of 0.25 was assumed for the coatings.

Tests of coatings adhesion were made using nanoindenter (NanoTest Vantage, Micro Materials Ltd., Wrexham, UK) and using the Berkovich indenter, as in the case of the nanoindentation tests.

The parameters of scratch tests were as follows: scratch load- -0 to $500 \mathrm{mN}$, loading rate$3.3 \mathrm{mN} / \mathrm{s}$, scan velocity $-3 \mu \mathrm{m} / \mathrm{s}$, and scan length $-500 \mu \mathrm{m}$. Based on the dependence of the friction force $(\mathrm{Ft})$ on the normal force $(\mathrm{Fn})$ in the program for the analysis of NanoTest results, the values of critical friction force (Lf) and critical force (Lc), which caused the separation of the layer from the substrate, were determined.

\subsection{Evaluation of Stability and Durability of Coating Materials in the Body Fluid Environment}

The analysis was carried out on Ag-enriched (a) titanium foil (Ti6Al4V, gradation 5, 99.7\% purity, STREM) and (b) titanium foil with tiatnium dioxide nanotube modified surface (i.e., arrangements $\mathrm{Ti} / \mathrm{Ag}$ and Ti/TNT5/Ag; Ti/TNT15/Ag; Ti/TNT20/Ag). Both variants were cut into $7 \mathrm{~mm} \times 7 \mathrm{~mm}$ pieces. These composites were additionally protected with polyglycolide (PGA) and were also analyzed. The prepared materials were immersed in $15 \mathrm{~mL}$ of buffered saline solution, with the concentration of ions and the osmotic pressure being comparable to that which prevails in human body fluids. This solution was made by dissolving a PBS tablet with the following composition: $140 \mathrm{mM} \mathrm{NaCl}$, $10 \mathrm{mM}$ phosphate buffer, $3 \mathrm{mM} \mathrm{KCl}$ in $100 \mathrm{~mL}$ distilled water. The samples were kept in an incubator at $310 \mathrm{~K}$ for 1, 2, 3, 4, 6, 7, 9, 10, 13, 14, 21, 26, 28, and 35 days. Estimation of silver concentration was performed by mass spectrometry with plasma ionization inductively coupled to a quadrupole analyzer using an ICP-MS 7500 CX spectrometer with Agilent Technologies collision chamber (Agilent Technologies Inc., Tokyo, Japan).

\section{Conclusions}

The direct result of our works was the fabrication of coatings that are composed of the dispersed AgNPs and/or the TNT/AgNPs nanocomposites on the surface of Ti6Al4V implants, produced in SLS technology. The TNT layers were produced using electrochemical anodization of Ti6Al4V at 5, 15, and $20 \mathrm{~V}$, while the CVD method was used in order to enrich Ti6Al4V and Ti6Al4/TNT substrates by silver nanoparticles. The carried out CVD experiments proved the utility of $\left.\left[\mathrm{Ag}_{5}\left(\mathrm{O}_{2} \mathrm{CC}_{2} \mathrm{~F}_{5}\right)_{5}\left(\mathrm{H}_{2} \mathrm{O}\right)_{3}\right)\right]$ as a precursor of metallic silver nanoparticles. The enrichment of Ti6Al4V and Ti6Al4V/TNT substrates with AgNPs increased their surface free energy, roughness, hardness, and Young's modulus. It also caused the increase of the hydrophobic properties. Studies of Ti6Al4V/TNT/AgNPs composites that were immersed in PBS solution proved that the concentration of silver ions released form the surface 
of these materials changes between 0.44 and 0.77 ppm after 35 days. This value is definitely below the critical level, which could have any negative effect on mammalian cells [35].

Supplementary Materials: Files containing crystallographic data were included as Supplementary Materials at http://www.mdpi.com/1422-0067/19/12/3962/s1.

Author Contributions: Conceptualization, P.P. and A.R.; Methodology, P.P., A.R., M.S., M.B.; Formal Analysis, A.R., M.E., M.S., T.M.M., P.P.; Investigation, A.R., T.M.M., M.G., M.E., M.B.; Writing-Original Draft Preparation, P.P.

Funding: This research was funded by the Regional Operational Programme of the Kuyavian-Pomeranian Voivodeship (1.3.1. Support for research and development processes in academic enterprises), within the grant obtained by Nano-implant Ltd.

Conflicts of Interest: The authors declare no conflict of interest.

\section{References}

1. Vorndran, E.; Moseke, C.; Gbureck, U. 3D printing of ceramic implants. MRS Bull. 2015, 40, 127-136. [CrossRef]

2. Imquist, A.; Omar, O.M.; Esposito, M.; Lausmaa, J.; Thomsen, P. Titanium oral implants: Surface characteristics, interface biology and clinical outcome. J. Roy. Soc. Interface 2010, 7, 515-527. [CrossRef] [PubMed]

3. Streckbein, P.; Streckbein, R.G.; Wilbrand, J.F.; Malik, C.Y.; Schaaf, H.; Howaldt, H.P.; Flach, M. Non-linear 3D Evaluation of Different Oral Implant-Abutment Connections. J. Dent. Res. 2012, 91, 1184-1189. [CrossRef] [PubMed]

4. Dekker, T.J.; Steele, J.R.; Federer, A.E.; Hamid, K.S.; Adams, S.B. Use of Patient-Specific 3D-Printed Titanium Implants for Complex Foot and Ankle Limb Salvage, Deformity Correction, and Arthrodesis Procedures. Foot Ankle Int. 2018, 36, 1-6. [CrossRef] [PubMed]

5. Tedesco, J.; Lee, B.E.J.; Lin, A.Y.W.; Binkley, D.M.; Delaney, K.H.; Kwiecien, J.M.; Grandfield, K. Osseointegration of a 3D Printed Stemmed Titanium Dental Implant: A Pilot Study. Int. J. Dent. 2017, 2017, 1-11. [CrossRef] [PubMed]

6. Shirazi, S.F.S.; Gharehkhani, S.; Mehrali, M.; Yarmand, H.; Metselaar, H.S.C.; Kadri, N.A.; Osman, N.A.A. A review on powder-based additive manufacturing for tissue engineering: Selective laser sintering and inkjet 3D printing. J. Sci. Technol. Adv. Mater. 2015, 16, 1-20. [CrossRef] [PubMed]

7. Tran, Q.H.; Nguyen, V.Q.; Le, A.T. Silver nanoparticles: Synthesis, properties, toxicology, applications and perspectives. Adv. Nat. Sci. Nanosci. Nanotechnol. 2013, 4, 1-20. [CrossRef]

8. Kang, C.G.; Park, Y.B.; Choi, H.; Oh, S.; Lee, K.W.; Choi, S.H.; Shim, J.S. Osseointegration of Implants Surface-Treated with Various Diameters of $\mathrm{TiO}_{2}$ Nanotubes in Rabbit. J. Nanomater. 2015, 2015, 1-11. [CrossRef]

9. Piszczek, P.; Lewandowska, Ż.; Radtke, A.; Jedrzejewski, T.; Kozak, W.; Sadowska, B.; Szubka, M.; Talik, E.; Fiori, F. Biocompatibility of Titania Nanotube Coatings Enriched with Silver Nanograins by Chemical Vapor Deposition. Nanomaterials 2017, 7, 1-19. [CrossRef]

10. Radtke, A.; Topolski, A.; Jędrzejewski, T.; Kozak, W.; Sadowska, B.; Więckowska-Szakiel, M.; Szubka, M.; Talik, E.; Nielsen, L.P.; Piszczek, P. The Bioactivity and Photocatalytic Properties of Titania Nanotube Coatings Produced with the Use of the Low-Potential Anodization of Ti6Al4V Alloy Surface. Nanomaterials 2017, 7, 1-15. [CrossRef]

11. Zhao, L.; Chu, P.K.; Zhang, Y.; Wu, Z. Antibacterial Coatings on Titanium Implants. J. Biomed. Mater. Res. 2009, 91, 470-480. [CrossRef] [PubMed]

12. Costerton, J.W.; Montanaro, L.; Arciola, C.R. Biofilm in implant infections: Its production and regulation. Int. J. Artif. Organs 2005, 28, 1062-1068. [CrossRef] [PubMed]

13. Fürst, M.M.; Salvi, G.E.; Lang, N.P.; Persson, G.R. Bacterial colonization immediately after installation on oral titanium implants. Clin. Oral Implants Res. 2007, 18, 501-508. [CrossRef] [PubMed]

14. Fielding, G.A.; Roy, M.; Bandyopadhyay, A.; Bose, S. Antibacterial and biological characteristics of silver containing and strontium doped plasma sprayed hydroxyapatite coatings. Acta Biomater. 2012, 8, 3144-3152. [CrossRef] [PubMed] 
15. Milić, M.; Leitinger, G.; Pavičić, I.; Avdičević, M.Z.; Dobrović, S.; Goessler, W.; Vrček, I.V. Cellular uptake and toxicity effects of silver nanoparticles in mammalian kidney cells. J. Appl. Toxicol. 2015, 35, 581-592. [CrossRef] [PubMed]

16. Feng, Q.L.; Wu, J.; Chen, G.Q.; Cui, F.Z.; Kim, T.N.; Kim, J.O. A mechanistic study of the antibacterial effect of silver ions on Escherichia coli and Staphylococcus aureus. J. Biomed. Mater. Res. 2000, 52, 662-668. [CrossRef]

17. Marambio-Jones, C.; Hoek, E.M.V. A review of the antibacterial effects of silver nanomaterials and potential implications for human health and the environment. J. Nanopart. Res. 2010, 12, 1531-1551. [CrossRef]

18. Dastjerdi, R.; Montazer, M. A review on the application of inorganic nano-structured materials in the modification of textiles: Focus on antimicrobial properties. Colloids Surf. B Biointerfaces 2010, 79, 5-18. [CrossRef]

19. Rai, M.K.; Deshmukh, S.D.; Ingle, A.P.; Gade, A.K. Silver nanoparticles: The powerful nanoweapon against multidrug-resistant bacteria. J. Appl. Microbiol. 2012, 112, 841-852. [CrossRef]

20. Franci, G.; Falanga, A.; Galdiero, S.; Palomba, L.; Rai, M.; Morelli, G.; Galdiero, M. Silver nanoparticles as potential antibacterial agents. Molecules 2015, 20, 8856-8874. [CrossRef]

21. Santillána, M.J.; Quarantab, N.E.; Boccaccinic, A.R. Titania and titania-silver nanocomposite coatings grown by electrophoretic deposition from aqueous suspensions. Surf. Coat. Technol. 2010, 205, 2562-2571. [CrossRef]

22. Akhavan, O.; Ghaderi, E. Self-accumulated Ag nanoparticles on mesoporous $\mathrm{TiO}_{2}$ thin film with high bactericidal activities. Surf. Coat. Technol. 2010, 204, 3676-3683. [CrossRef]

23. Yates, H.M.; Brook, L.A.; Sheel, D.W. Photoactive Thin Silver Films by Atmospheric Pressure CVD. Int. J. Photoenergy 2008, 1-8. [CrossRef]

24. Golrokhi, Z.; Chalker, S.; Sutcliffe, C.J.; Potter, R.J. Self-limiting atomic layer deposition of conformal nanostructured silver films. Appl. Surf. Sci. 2016, 364, 789-797. [CrossRef]

25. Grodzicki, A.; Łakomska, I.; Piszczek, P.; Szymańska, I.; Szłyk, E. Copper(I), silver(I) and gold(I) carboxylate complexes as precursors in chemical vapour deposition of thin metallic films. Coord. Chem. Rev. 2005, 249, 2232-2258. [CrossRef]

26. Dryden, N.H.; Vittal, J.J.; Puddephatt, R.J. New precursors for chemical vapor deposition of silver. Chem. Mater. 1993, 5, 765-766. [CrossRef]

27. Piszczek, P.; Szłyk, E.; Chaberski, M.; Taeschner, C.; Leonhardt, A.; Bała, W.; Bartkiewicz, K. Characterization of Silver Trimethylacetate Complexes with Tertiary Phosphines as CVD Precursors of Thin Silver Films. Chem. Vap. Depos. 2005, 11, 53-59. [CrossRef]

28. Szłyk, E.; Piszczek, P.; Chaberski, M.; Goliński, A. Studies of thermal decomposition process of Ag(I) perfluorinated carboxylates with temperature variable IR and MS. Polyhedron 2001, 20, 2853-2861. [CrossRef]

29. Szłyk, E.; Piszczek, P.; Grodzicki, A.; Chaberski, M.; Goliński, A.; Szatkowski, J.; Błaszczyk, T. CVD of AgI Complexes with tertiary Phosphines and Perfluorinated Carboxylates-A New Class of Silver Precursors. Chem. Vap. Dep. 2001, 7, 1-6.

30. Lutz, H.D. Bonding and structure of water molecules in solid hydrates. Correlation of spectroscopic and structural data. In Solid Materials; Structure and Bonding; Springer: Berlin/Heidelberg, Germany, 1988; Volume 69, pp. 97-125.

31. Lewandowska, Ż.; Piszczek, P.; Radtke, A.; Jedrzejewski, T.; Kozak, W.; Sadowska, B. The evaluation of the impact of titania nanotube covers morphology and crystal phase on their biological properties. J. Mater. Sci. 2015, 26, 163. [CrossRef]

32. Brammer, K.S.; Oh, S.; Cobb, C.J.; Bjursten, L.M.; van der Heyde, H.; Jin, S. Improved bone forming functionality on diameter-controlled $\mathrm{TiO}_{2}$ nanotube surface. Acta Biomater. 2009, 5, 215-3223. [CrossRef] [PubMed]

33. Caihong, L.; Jiang, W.; Xiaoming, L. A visible-light-controlled platform for prolonged drug release based on Ag-doped $\mathrm{TiO}_{2}$ nanotubes with a hydrophobic layer. Beilstein J. Nanotechnol. 2018, 9, 1793-1801. [CrossRef]

34. Piszczek, P.; Radtke, A. Silver Nanoparticles Fabricated Using Chemical Vapor Deposition and Atomic Layer Deposition Techniques: Properties. Applications and Perspectives: Review. In Noble and Precious Metals; Seehra, M.S., Bristow, A.D., Eds.; IntechOpen: London, UK, 2018; pp. 187-213, ISBN 978-1-78923-292-9.

35. Antoci, V., Jr.; Adams, C.S.; Parvizi, J.; Davidson, H.M.; Composto, R.J.; Freeman, T.A.; Wickstrom, E.; Ducheyne, P.; Jungkind, D.; Shapiro, I.M.; et al. The inhibition of Staphylococcus epidermidis biofilm formation by vancomycin-modified titanium alloy and implications for the treatment of periprosthetic infection. Biomaterials 2008, 29, 4684-4690. [CrossRef] [PubMed] 
36. Zaho, C.; Feng, B.; Li, Y.; Tan, J.; Lu, X.; Weng, J. Preparation and antibacterial activity of titanium nanotubes loaded with Ag Nanoparticles in the dark and under the UV light. Appl. Surf. Sci. 2013, 280, 8-14. [CrossRef]

37. Von Wilmowsky, C.; Bauer, S.; Lutz, R.; Meisel, M.; Neukam, F.W.; Toyoshima, T.; Schmuki, P.; Nkenke, E.; Schlegel, K.A. In vivo evaluation of anodic $\mathrm{TiO}_{2}$ nanotubes: An experimental study in the pig. J. Biomed. Mater. Res. Part B Appl. Biomater. 2008, 89B, 165-171. [CrossRef] [PubMed]

38. Kim, D.; Lee, K.; Roy, P.; Birajdar, B.I.; Spiecker, E.; Schmuki, P. Formation of a Non-Thickness-Limited Titanium Dioxide Mesosponge and its Use in Dye-Sensitized Solar Cells. Angew. Chem. 2009, 121, 9490-9493. [CrossRef]

39. Lee, K.; Kim, D.; Roy, P.; Paramasivam, I.; Birajdar, B.I.; Spiecker, E.; Schmuki, P. Anodic Formation of Thick Anatase $\mathrm{TiO}_{2}$ Mesosponge Layers for High-Efficiency Photocatalysis. J. Am. Chem. Soc. 2010, 132, 1478-1479. [CrossRef] [PubMed]

40. Regonini, D.; Satka, A.; Jaroenworaluck, A.; Allsopp, D.W.E.; Bowen, C.R.; Stevens, R. Factors influencing surface morphology of anodized $\mathrm{TiO}_{2}$ nanotubes. Electrochim. Acta 2012, 74, 244-253. [CrossRef]

41. Macak, J.M.; Hildebrand, H.; Marten-Jahns, U.; Schmuki, P. Mechanistic aspects and growth of large diameter self-organized $\mathrm{TiO}_{2}$ nanotubes. J. Electroanal. Chem. 2008, 621, 254-266. [CrossRef]

42. Bauer, S.; Kleber, S.; Schmuki, P. $\mathrm{TiO}_{2}$ nanotubes: Tailoring the geometry in $\mathrm{H} 3 \mathrm{PO} 4 / \mathrm{HF}$ electrolytes. Electrochem. Commun. 2006, 8, 1321-1325. [CrossRef]

43. Kar, A.; Raja, K.S.; Misra, M. Electrodeposition of hydroxyapatite onto nanotubular $\mathrm{TiO}_{2}$ for implant applications. Surf. Coat. Technol. 2006, 201, 3723-3731. [CrossRef]

44. Xiong, J.; Wang, Y.; Li, Y.; Hodgson, P. Phase transformation and thermal structure stability of titania nanotube films with different morphologies. Thin Solid Films 2012, 526, 116-119. [CrossRef]

45. Yang, B.; Ng, C.K.; Fung, M.K.; Ling, C.C.; Djurišić, A.B.; Fung, S. Annealing study of titanium oxide nanotube arrays. Mater. Chem. Phys. 2011, 130, 1227-1231. [CrossRef]

46. Kaczmarek, D.; Domaradzki, J.; Wojcieszak, D.; Prociow, E.; Mazur, M.; Placido, F.; Lapp, S. Hardness of Nanocrystalline $\mathrm{TiO}_{2}$ Thin Films. J. Nano Res. 2012, 18-19, 195-200. [CrossRef]

47. Wojcieszak, D.; Mazur, M.; Indyka, J.; Jurkowska, A.; Kalisz, M.; Domanowski, P.; Kaczmarek, D.; Domaradzki, J. Mechanical and structural properties of titanium dioxide deposited by innovative magnetron sputtering process. Mater. Sci.-Poland 2015, 33, 660-668. [CrossRef]

48. Oh, K.; Lee, K.; Choi, J. Influence of geometry and crystal structures of $\mathrm{TiO}_{2}$ nanotubes on micro Vickers hardness. Mater. Lett. 2017, 192, 137-141. [CrossRef]

49. Munirathinam, B.; Neelakantan, L. Role of crystallinity on the nanomechanical and electrochemical properties of $\mathrm{TiO}_{2}$ nanotubes. J. Electroanal. Chem. 2016, 770, 73-83. [CrossRef]

50. Sheldrick, G.M. Crystal structure refinement with SHELXL. Acta Cryst. 2015, C71, 3-8. [CrossRef]

51. Brandenburg, K. DIAMOND, Release 2.1e.; Crystal Impact GbR: Bonn, Germany, 2001.

52. Farrugia, L.J. WinGX and ORTEP for Windows: An update. J. Appl. Crystallogr. 2012, 45, 849-854. [CrossRef] 